Portland State University

PDXScholar

Spring 6-10-2016

\title{
Transgender Patients' Experiences of Discrimination at Mental Health Clinics
}

Corrine Ann Stocking

Portland State University

Follow this and additional works at: https://pdxscholar.library.pdx.edu/open_access_etds

Part of the Lesbian, Gay, Bisexual, and Transgender Studies Commons, Psychiatric and Mental Health Commons, and the Sociology Commons

Let us know how access to this document benefits you.

\section{Recommended Citation}

Stocking, Corrine Ann, "Transgender Patients' Experiences of Discrimination at Mental Health Clinics" (2016). Dissertations and Theses. Paper 2993.

https://doi.org/10.15760/etd.2994

This Thesis is brought to you for free and open access. It has been accepted for inclusion in Dissertations and Theses by an authorized administrator of PDXScholar. Please contact us if we can make this document more accessible: pdxscholar@pdx.edu. 
Transgender Patients' Experiences of Discrimination at Mental Health Clinics

by

Corrine Ann Stocking

A thesis submitted in partial fulfillment of the requirements for the degree of

Masters of Science

in

Sociology

Thesis Committee:

Melissa Thompson, Chair

Maura Kelly

Amy Lubitow

Portland State University

2016 


\begin{abstract}
The transgender population is makes up about $0.3 \%$ of the U.S. population (Gates 2011). The term transgender is both an identity and an umbrella term used to describe people who do not adhere to traditional gender norms (Institute of Medicine 2011). Transgender people experience many barriers to services, negative health outcomes, and discrimination (Fredrikson-Goldsen et al. 2013; Institute of Medicine 2011; Eliason et al. 2009; Hendricks \& Testa 2012). Mental health clinics are an important site for understanding transgender people's experiences due to being a gatekeeper for other medical services and their role in helping transpeople with issues surrounding coming out, victimization, and discrimination (Grant et al. 2011; Youth Suicide Prevention Program 2011). The mental health field has a contested relationship with the transgender population due to a history of pathologizing gender variance, barriers to accessing services, and insensitivity from mental health providers (American Psychiatric Association 2013; Eliason et al. 2009). I conducted secondary data analysis using the National Transgender Discrimination Survey (2008) in order to understand the relationships between gender non-conforming identities, others' perception of one's gender identity, and discrimination at mental health clinics. Results suggest that there is an association between gender identity, others' perception of one's gender identity, and discrimination. This association depends on which gender identity, the degree to which an individual identifies with each term, and the type of discrimination. Logistic regression results reveal that identity and others' perception are not significant predictors for experiencing discrimination. Rather, income and race are significant predictors for experiencing discrimination at metal health clinics.
\end{abstract}




\section{TABLE OF CONTENTS}

ABSTRACT

LIST OF TABLES

LIST OF FIGURES

IV

INTRODUCTION

THEORETICAL FRAMEWORK

MINORITY STRESS

GENDER

LITERATURE REVIEW

GENDER: DEFINITIONS, CONCEPTS, AND TRANSGENDER IDENTITY

INTERACTIONS IN GENERAL

INTERACTIONS WITH THE HEALTH CARE SYSTEM

INTERACTIONS WITH THE MENTAL HEALTH SYSTEM

METHODS

INDEPENDENT VARIABLE

DEPENDENT VARIABLE

RESULTS

BIVARIATE ANALYSES OF IDENTITY BY PERCEPTION OF TRANS IDENTITY

BIVARIATE ANALYSES OF IDENTITY BY DISCRIMINATION

MULTIVARIATE ANALYSES

DISCUSSION

GENDER IDENTITY AND DISCRIMINATION

OTHERS' PERCEPTION AND DISCRIMINATION

LIMITATIONS

FUTURE RESEARCH

CONCLUSION 


\section{LIST OF TABLES}

$\begin{array}{ll}\text { Table } 1 & 42\end{array}$

Table $2 \quad 54$

Table $3 \quad 56$

Table $4 \quad 57$

Table $5 \quad 58$

Table $6 \quad 59$

Table $7 \quad 60$

Table $8 \quad 61$

$\begin{array}{ll}\text { Table } 9 & 62\end{array}$

Table $10 \quad 63$ 


\section{LIST OF FIGURES}

$\begin{array}{ll}\text { Chart } 1 & 40\end{array}$

Chart $2 \quad 44$

Chart $3 \quad 46$

Chart $4 \quad 49$

Chart $5 \quad 51$

Chart $6 \quad 54$

Chart $7 \quad 56$

Chart $8 \quad 57$ 


\section{INTRODUCTION}

The experiences of the transgender community have largely been underresearched. Research has estimated there are approximately 700,000 transgender individuals in the U.S. or about .3\% of the population (Gates 2011). Estimates of the number of transgender persons in the United States vary due to both varying definitions of transgender identity and a lack of consistency in surveys that ask questions regarding gender identity (Gates 2011). There is a need for more research on the transgender population because they vary in identity, experience negative mental health outcomes, and lack federal protection. Mental health clinics are an important site for understanding transpeople's experiences because improving their experiences at mental health clinics can also help to improve their overall outcomes.

The term transgender is used to describe many people and definitions vary within the transgender community (National Center for Transgender Equality 2014; Institute of Medicine 2011). In general, the word transgender is used to describe persons who "depart significantly from traditional gender norms" (Institute of Medicine 2011:26). This term includes persons such as transgender man (someone who transitions from female to male), transgender woman (someone who transitions from male to female), and gender non-conforming (gender expression is different from gender norms associated with their sex assigned at birth) (National Center for Transgender Equality 2014; Institute of Medicine 2011). Terms for gender identity have varied over time and include older terms such as transsexual and newer terms such as genderqueer (Schilt 2010). 
For all of these identities, sex and gender are important both for the individual and their interactions with others. The term sex is often established as having a biological foundation, which then creates a social division that is salient for individuals identifying by these categories (Ridgeway 2011; Epstein 2007; Brickell 2006). Gender is a social construction where individuals "do" gender as a performance in order to reproduce and legitimize the initial divisions of one's sex (West \& Zimmerman 1987). This is important for transgender and gender non-conforming people, as their experiences do not fit perfectly in the gender binary that aligns with one's sex assigned at birth.

When one's gender identity or expression do not fit within the binary, there can be real consequences that can occur such as discrimination and negative health outcomes. The Institute of Medicine (2011) released the first government issued book on LGBT health, which emphasized a need for more research to be conducted on LGBT populations and specifically called to understand transgender experiences with discrimination within the health care system (Institute of Medicine 2011). This includes the mental health care system, which is often the gatekeeper to medical procedures for transitioning and the provider for general services to help transgender persons cope with discrimination, coming out, and other life events that put them at high risk for suicide (Grant et al. 2011; Youth Suicide Prevention Program 2011). While the mental health field can help the transgender population, it can also be a site for further discrimination and stigmatization. The mental health field historically pathologized gender variance, where for almost twenty years transpeople were diagnosed with gender identity disorder (American Psychiatric Association 2013). Pathologizing gender variance has often resulted in the fear of diagnosis or judgment that can prevent transpeople from seeking 
services or fabricating a "correct" story of wanting to transition in order to receive medical services for transitioning (Cooks-Daniels 1998). In 2013, the American Psychiatric Association released a new edition of the diagnostic manual (DSM-V), which changed diagnoses people who identify with a gender different from their gender assigned at birth as having gender dysphoria. This change was made in attempt to destigmatize gender variance, but still allow transgender and gender non-conforming individuals the ability to receive some diagnosis in order to comply with insurance standards to receive medical treatments (such as hormone therapy, etc.).

Transpeople experience discrimination within the health care system such as being denied services, challenges to accessing health care, and verbal abuse. While this population is at risk for discrimination, there is no federal law that explicitly protects transgender persons based on gender identity/expression (HRC 2013; Equal Employment Opportunity Commission). Rather, when transpeople experience discrimination it is considered to be discrimination based on sex (HRC 2013; U.S. Equal Employment Opportunity Commission). Sex-based discrimination is defined as the unfavorable treatment of someone due to their sex or affiliation with a group associated with a certain sex (Equal Employment Opportunity Commission). Sex discrimination harassment can also occur, in which unwelcome sexual advances or non-sexual offensive comments are made about a person's sex (Equal Employment Opportunity Commission). Transpeople are therefore lacking protection since the federal law does not explicitly protect gender identity or expression. Their risk for discrimination is further exacerbated by cultural expectations of how to "do" gender (West \& Zimmerman 1987). 
My research seeks to consider transgender people's experiences of discrimination within the health care system, specifically mental health clinics. This is in line with the Institute of Medicine's (2011) suggestion to prioritize understanding transgender specific health needs, including their experiences of discrimination in the health care system. Mental health clinics serve as an important site for understanding transpeople's experiences as they serve as a gatekeeper to other medical services and can help with coming out, victimization, and discrimination (Grant et al. 2011; Youth Suicide Prevention Program 2011). There is also little research on the variety of transgender identities (Gates 2011). Therefore, this study will address the various gender identities within the transgender population and their experiences of discrimination at mental health clinics. Specifically, this study will address the following research questions:

1. How do various gender identities, among gender non-conforming individuals, affect perceived discrimination at mental health clinics?

2. How does others' perception of gender non-conformity affect transgender and gender non-conforming individuals' reports of discrimination at mental health clinics? 


\section{THEORETICAL FRAMEWORK}

Previous research reveals that the transgender and gender nonconforming populations experience negative mental health outcomes and problems with the mental health care system. What is known about transpeople's interactions with the health care system includes:

1. Transpeople have mental health concerns that are both similar to the general population (daily stressors, etc.) and unique concerns due to their gender identity (coming out, transitioning, victimization, discrimination) (Grant et al. 2011; Eliason et al. 2009; Gamarel et al. 2014; Hendricks \& Testa 2012).

2. Transpeople experience challenges accessing health care and treatment by health care providers (insensitivity, lack of knowledge, etc.) (Fredrikson-Goldsen et al. 2013; Institute of Medicine 2011; Eliason et al. 2009).

Due to a conflation with LGB (lesbian, gay, bisexual) populations, transgender people are often assumed to have experiences identical to those of LGB persons. Transgender people have similar experiences to sexual minorities and may even identify as LGB, but their gender identity or expression create distinct experiences that are important to understand. Social psychological perspective, symbolic interactionist perspective, and minority stress theory are important for this study. These perspectives help to frame why transpeople's experiences with the mental health care system are important, why people would discriminate based on gender, and why differences within the transgender population are important (Meyer 2003; Henricks and Testa 2012; Schilt 2010; Connell 2010; West and Zimmerman 1987; Ridgeway 2011). 


\section{Minority Stress}

Meyer (2003) defines minority stress as trying to distinguish "the excess stress to which individuals from stigmatized social categories are exposed as a result of their social, often minority, position" (3). Meyer's (2003) minority stress model for lesbian, gay, and bisexual (LGB) populations begins with the discussion of classifying homosexuality as a mental disorder. Meyer (2003) points out that pathologizing homosexuality is more of a question of classification and considering what behaviors or emotions are indicators of a mental disorder. The fact that sexual minorities experience mental health disorders is not the issue, but rather that stigmatizing individuals due to their sexual identity unsurprisingly can result in impaired self-image and unhappiness (Meyer 2003). Even with the removal of homosexuality from the second edition of the DSM, Meyer (2003) notes that it is important to understand this risk for excess mental distress and disorders and the factors that can improve stress and mental health.

Minority stress helps to frame the excess of mental disorders among LGB people by explaining that "stigma, prejudice, and discrimination create a hostile and stressful social environment that causes mental health problems" (Meyer 2003:1). Minority stress is based on the assumptions that this stress is in addition to the stressors that all people experience, it is chronic and related to relatively stable structures, and it is socially based such that it is beyond the individual and stems from social processes, institutions, and structures (Meyer 2003). Four processes of minority stress that are relevant to LGB individuals include: a) objective stressful events and conditions, b) expectations that these events will occur, c) internalized stigma (internalized homophobia), and d) concealing one's sexual orientation (Meyer 2003). Meyer (2003) points out that these processes can 
result in the excess of mental health problems and outcomes, such as suicide, but they can also lead to resources that protect minorities from the adverse mental health affects. For example, experiencing minority stress can help individuals through group solidarity (such as an LGB person being involved in the LGB community) and resilience by learning to cope with the stress (Meyer 2003). Although Meyer's (2003) minority stress model for LGB populations did not directly include transgender and gender nonconforming populations, it is useful for framing our understanding of transgender people in the health care system. Meyer's (2003) discussion of the LGB population parallels the experiences of the transgender population. Similar to sexual minorities, transgender people experienced being diagnosed with a mental disorder due to their gender variance. Transgender people experience stigmatization and an excess of mental health problems, such as suicide. Minority stress frames why discrimination is important, as it can be the cause of the excess in mental health problems. Minority stress is particularly important when considering mental health clinics, as they are the site where people could get help for the excess of mental health problems.

Hendricks and Testa (2012) extend on Meyer's (2003) minority stress model to provide a framework for clinical work with transgender and gender nonconforming clients. Hendricks and Testa (2012) note that the minority stress model is applicable to transgender and gender nonconforming persons because this population reports high levels of physical and sexual violence, high rates of substance abuse, and suicide ideation and attempts due to external negative events (victimization and discrimination related to gender identity). The inclusion of transgender and gender nonconforming populations in the minority stress model is based on previous research that indicates a relationship 
between victimization and negative health outcomes (suicide) and concealment of identity (Hendricks \& Testa 2012). Therefore, the excess of prevalence of disorders and negative health outcomes for transgender and gender nonconforming individuals can be explained through minority stress.

The prevalence of victimization and discrimination transpeople experience creates a stressful social environment. This is important for the current study as it provides a framework as to why studying discrimination at mental health clinics is important. Previous research that utilizes the minority stress model focuses on the negative health outcomes, whereas the current study focuses on differences between transgender identities (transman, transwoman, etc.) and discrimination in one location. The variation of transgender identities is important for future studies utilizing minority stress theory, as previous research on transpeople does not always fully consider the variation of identities in the transgender community. The variation of transgender identities is important as new terms for gender identity emerge, such as the rise in popularity with identifying as genderqueer since the early 2000s (Schilt 2010). By excluding these newer gender identities, it is possible that research would be missing significant experiences that are taking place within the transgender community. It is also possible that by using only umbrella terms (transgender) or terms that are no longer as popular (FTM or MTF instead of transman or transwoman), research could then unintentionally limit the results to a specific age cohort that identifies with older terminology (such as transsexual).

Minority stress helps to show how looking at discrimination in mental health clinics can be important, given there can be negative outcomes if there is discrimination occurring at mental health clinics. For example, discrimination at mental health clinics 
can be a form of secondary discrimination, where a person experiences discrimination from the person they are seeking help from (mental health providers). This can lead them to expecting that these events will occur. They can internalize the stigma if the events occur, utilize coping skills or enhance group solidarity, or conceal their identity to mental health providers.

\section{Gender}

The visibility of one's gender is dependent on how others perceive an individual's gender presentation. Ridgeway (2011) argues that gender is one primary frame for interactions. During an interaction, we first categorize the other person into a specific gender and use that as a frame for how we should interact with that person (Ridgeway 2011). Ridgeway's (2011) discussion of gender as a primary frame assumes an expectation that someone will behave and present according to a specific gender. West and Zimmerman (1987) discuss this expectation by describing gender as a performance that individuals "do." The purpose of this performance is to help legitimize and reproduce the initial divisions of one's sex (West and Zimmerman 1987). Doing gender is also evaluated by others, such as its use as a primary frame for interactions, which helps to affirm or deny an individual's ability to pass as their sex assigned at birth. The power of this evaluation comes from both the ability for others to evaluate and self-regulation, meaning the ability to conform to gender ideals is constantly under scrutiny (West and Zimmerman 1987).

Gender operates in a reflexive relationship with a person's sex assigned at birth to help form identities (West and Zimmerman 1987). For example, a person who is transgender would be assigned a sex category at birth (male or female). Their sex 
assigned at birth would be in a reflexive relationship with their gender identity and expression, one that is opposite from or does not conform with the gender associated with their sex assigned at birth. This would help to shape their identity, where they could later identify as transgender. Miller and Grollman (2015) emphasize that gender nonconformity, a visible marker of being transgender, heightens these experiences of being evaluated due to their gender identity. Schilt (2010), West and Zimmerman (1987), and Miller and Grollman (2015) are important for the present study in that they frame how discrimination could occur. Gender being used as a primary frame for interactions and a transperson's gender performance being evaluated can create a situation where victimization and discrimination occur due to gender identity.

Differences within the transgender population are important to consider. Schilt (2010), Connell (2010), and Miller and Grollman (2015) provide a framework as to why differences among the transgender population are important. Both Schilt (2010) and Connell (2010) examine transpeople's experiences at work. Using West and Zimmerman's (1987) doing gender theory, Connell (2010) argued that "doing transgender" captures transpeople's experiences of performing gender, as it can take form similarly to "doing gender" or "undoing/redoing gender." For example, transpeople performing stealth in the workplace were held to the same gender expectations as cisgender people (people whose gender and sex assigned at birth coincide). Transpeople, especially participants who identified as genderqueer, who were out at work often tried to create a hybrid of gender expression, sometimes for political meaning or to feel like they were maintaining their authentic self. Many of Schilt's (2010) findings reinforce Connell's (2010) findings that transpeople have varying experiences. Schilt (2010) found 
that workplace experiences are different for transmen than they are for transwomen. Transwomen have reported experiencing barriers at work, such as not being able to use the women's restroom, being told to not dress in feminine clothing, or experiencing their competence being questioned (Schilt 2010). In contrast, transmen have reported increased economic opportunities and being promoted quickly (Schilt 2010).

Miller and Grollman (2015) draw on Meyer's (2003) minority stress theory to understand the connections between gender nonconformity, discrimination, and negative health outcomes (suicide, drug/alcohol abuse, etc.). Using cross-sectional data from the National Transgender Discrimination Survey, they found that gender nonconforming transpeople face more discrimination and have more negative health outcomes than trans people who are gender conforming (Miller \& Grollman 2015). Miller and Grollman (2015) provide justification for considering various groups within the transgender community, given that it is not merely a transgender identity that can cause heightened discrimination, but being visibly gender nonconforming that is important to consider. Schilt (2010), Connell (2010), and Miller and Grollman (2015) are important for this study because they provide a framework of why it is important to consider varying identities within the transgender community. Performing stealth and the extent to which an individual conforms to traditional gender presentations is important in the evaluation of gender that Ridgeway (2011) and West and Zimmerman (1987) emphasize.

I utilized both the symbolic interactionist (West \& Zimmerman 1987) and social psychology (Ridgeway 2011) perspectives in order to discuss my results. These perspectives compliment each other by explaining how people's behaviors (such as discriminating against another) are influenced by the presence of others (such as a 
transgender or gender non-conforming person). These behaviors (discrimination) are influenced by the meanings an individual ascribes to that situation, often due to social interactions and interpretation of a situation. For example, when an individual meets a transgender person they first categorize them into a specific gender, which helps to frame how they should interact with them (Ridgeway 2011). During the interaction, the individual's behavior toward a transperson is influenced by a performance that is expected to legitimize and reproduce the initial division of one's sex (West \& Zimmerman 1987). When one is unable to pass as their sex assigned at birth, such as being visibly gender non-conforming, there is a possibility that the transgender person will be treated poorly due to the initial framing of gender and the evaluation of their gender performance (Ridgeway 2011; West \& Zimmerman 1987; Miller \& Grollman 2015). These perspectives provide support for exploring how transpeople's identity and gender expression play a role in their experiences of discrimination at mental health clinics. 


\section{LITERATURE REVIEW}

Gender: Definitions, Concepts, and Transgender Identity

As described in the theoretical framework, gender is important for our

understanding of transgender identity for the following reasons:

1. Everyone is assigned a sex at birth that may or may not correspond to their gender identity or expression. For transgender people, their gender identity does not fully align with their sex assigned at birth.

2. As a social construction, gender is a performance and a way to frame social interactions with others (West \& Zimmerman 1987; Ridgeway 2011).

3. Gender is evaluated in interactions with others.

Using gender as a primary frame for interactions and to evaluate how well people "do" gender can lead to discriminatory acts, such as verbal antagonism (Ridgeway 2011; West \& Zimmerman 1987). These discriminatory acts can include slurs and comments about a group, such as transgender people, that can act as an evaluation of whether someone adheres to gender norms.

Terms used to describe gender identity vary among community and age (National Center for Transgender Equality 2014; Institute of Medicine 2011). Transgender is both a term for an identity and a term used to describe many people who do not fit within the gender binary, such as transmen and transwomen. In general, the word transgender is used to describe persons who "depart significantly from traditional gender norms" (Institute of Medicine 2011:26). Traditional gender norms assume that a person's gender identity and expression is concordant with the sex they were assigned at birth. Fredriksen-Goldsen et al. (2013) emphasize a difference between gender identity and 
gender expression, where gender identity is an individual's feeling of their gender and gender expression is how a person expresses gender and others then perceive their gender. The distinction between identity and expression is important, because a transgender person may identify with a specific identity (such as FTM) and be stealth (pass as a binary gender) or visibly gender non-conforming. Gender expression and identity can ultimately influence the outcome of their social interactions with others.

The term transgender can include many identities such as transman (someone who transitions from female to male; FTM), transwoman (someone who transitions from male to female; MTF), and gender non-conforming (gender expression is different from gender norms associated with their sex assigned at birth) (National Center for Transgender Equality 2014; Institute of Medicine 2011). Terms such as transman and FTM are often used interchangeably (Schilt 2010). Cook-Daniels (1998) notes that the term transgender is relatively new, and therefore is not a term that transpeople of all ages will necessarily identify with. Transsexuals "desire or have had hormone therapy and/or surgery to feminize or masculinize their body and may live full time in their cross-gender role" (Institute of Medicine 2011:26). The term transsexual developed in the 1940s in the psychological community, but the term transgender emerged from activism in the 1990s (Schilt 2010). Some people who identify as transsexual differentiate themselves from transgender people in order to emphasize that they are not gender variant, rather they fully identify with the other gender than their gender assigned at birth (Institute of Medicine 2011). Compared to those who identify as transgender or gender nonconforming, transsexuals have been more focused on in previous research because they are more accessible due to being more likely to seek medical services (Institute of 
Medicine 2011). As of the early 2000s, terms such as genderqueer have also been used to describe individuals who blend both masculine and feminine gender norms, regardless of any physical modifications (Schilt 2010). Connell (2010) defines genderqueer as blending gender presentations, pronouns, and self-concepts, which is often politically motivated. The term queer is used to refer to either sexual or gender minorities, and therefore some people within the transgender and gender non-conforming community identify as queer (National Center for Transgender Equality 2014).

There are multiple other gender non-conforming identities that are used to describe gender variance, or possessing both masculine and feminine qualities, or possessing qualities that are neither masculine or feminine. Gender non-conforming is both an identity and an umbrella term that describes individuals whose gender expression does not fit societal norms for gender (National Center for Transgender Equality 2014). Gender non-conforming identities can also include identities such as non-binary, gender fluid, or bi-gendered (gender encompasses both genders). However, little is known about individuals who identify with these terms (and other gender non-conforming terms) which may be due to few people identifying with these terms, research being unable to access these communities, or the fluidity of many of these terms resulting in a lack of definition of who is a part of these identities and who is not.

Some transpeople may not identify with transgender or gender nonconforming identities, but rather only see themselves as their new or current gender identity, such as a transman who may identify as "male" rather than "trans" (Sperber et al. 2005). This is in accordance with performing stealth, meaning an individual does not identify as transgender and to their knowledge are not read as being transgender; they perform 
gender that masks that their gender and sex assigned at birth do not coincide and are therefore left to navigate doing gender similarly to cisgender people (Connell 2010).

Given the varying meanings of trans identity based on age, community, or even an individual's preference, it can quickly pose a problem for the frame of how an interaction takes place (National Center for Transgender Equality 2014; Institute of Medicine 2011; Cook-Daniels 1998; Ridgeway 2011). For a cisgender person who may not be educated on varying gender identities, they could quickly assume the "wrong" gender identity for a transgender or gender nonconforming person. Even for people who understand there are varying gender identities, it is possible to accidentally assume another person's gender identity or preferred gender pronouns. This can occur during any interaction and previous research has considered the experiences of transpeople at work, in health care settings, and mental health care settings.

Using West and Zimmerman's (1987) theory of “doing gender," Connell (2010) examined transpeople's experiences at work. Under the theory of doing gender, people perform gender in order to reproduce and legitimize the initial divisions of one's sex (West \& Zimmerman 1987). Connell (2010) found that transpeople not only contribute to "doing gender," but rather can contribute to the doing, undoing, or redoing of gender. Specifically, transpeople performing stealth in the workplace fit under the theory of doing gender. Their stealth performance by not identifying as trans and to their knowledge, not being perceived as trans, has left them accountable to the same structures of doing gender as cisgender people. In contrast, transpeople who were more "out" at work could be interpreted as "undoing" or "redoing" gender by resisting pressures and created a hybrid of gender through interactions (Connell 2010). A person could create a hybrid gender 
performance by adopting traits or behaviors that are perceived to be feminine and masculine. For example, some of Connell's (2010) participants who presented primarily as male would talk with their hands, ask about other's feelings, or choose to not do testosterone in order to have softer features that prevented them from being read exclusively as male. These strategies helped to challenge what it is to be a man and sometimes confused others on their gender, therefore "undoing" or "redoing" gender.

\section{Interactions in General}

Transgender people have experienced gender inequality and discrimination, both from society at large and even within the LGBTQ community. Transpeople also have little legal protections, as there is no current federal law that specifically protects transgender people from discrimination (HRC 2013; Equal Employment Opportunity Commission). There is limited research on transgender identities and their experiences. The majority of previous research that does address transgender people focuses on lesbian, gay, bisexual, and transgender (LGBT) experiences as a whole, and therefore conflates these identities as having similar experiences. Previous research on LGBT people has typically focused on gay men and sometimes on lesbians (Nadal 2013). This research then assumes that their findings are applicable to transpeople, but often do not even have any trans participants (Nadal 2013). My study looks solely at transgender and gender nonconforming people in order to better understand their specific experiences, separate of the experiences of LGB people.

Transpeople's experiences in the workforce is one area that has some previous research. While this study focuses on mental health clinics, previous research of transpeople's experience at work provides insight into one aspect of transpeople's lives 
and theoretical implications of how to understand transpeople's experiences and identities. Both Schilt (2010) and Connell (2010) looked at transpeople's experiences at work. Connell (2010) was primarily focused on expanding West and Zimmerman's (1987) doing gender theory. By doing in-depth interviews, Connell (2010) argued that "doing transgender" captures transpeople's experiences of performing gender, as it can take form similarly to "doing gender" or "undoing/redoing gender." For example, transpeople performing stealth in the workplace were held to the same gender expectations as cisgender people (people whose gender and sex assigned at birth coincide). Transpeople, especially participants who identified as genderqueer, who were out at work often tried to create a hybrid of gender expression, sometimes for political meaning or to feel like they were maintaining their authentic self. Connell (2010) notes that "redoing" or "undoing" gender is used to challenge naturalized notions of gender, but does not do away with gender as a method of sorting or organization for society, or the workplace.

Schilt (2010) also interviewed transpeople and found that they experience gender inequality in the workplace. Many of Schilt's (2010) findings reinforce Connell's (2010) idea that transpeople can challenge gender, but not gender as a mechanism for sorting. Schilt (2010) found that workplace experiences are different for transmen than they are for transwomen. Transwomen have reported experiencing barriers at work, such as not being able to use the women's restroom, being told to not dress in feminine clothing, or experiencing their competence being questioned (Schilt 2010). In contrast, transmen have reported increased economic opportunities and being promoted quickly (Schilt 2010). While Schilt's (2010) research reveals interactions in the workplace, she notes that the 
workplace is one institution that reveals how gender inequality is reproduced structurally. Even with the acceptance of transmen at work, this contributes to the maintenance of the gender status quo (Schilt 2010). Educated, white transmen who physically passes as men are able to benefit from the subordination of women (and transwomen) because there are benefits of a person's race and gender regardless of their intentions (Schilt 2010). This means that gender boundaries can shift on an individual level, but it does not necessarily mean that the structural or cultural beliefs about gender are being challenged (Schilt 2010). For the current study, Schilt (2010) provides an example of why to consider differences between transgender identities, such as transmen and transwomen. Connell's (2010) research suggests that whether or not a transperson believes others perceive them to be transgender is also an important component, as being stealth versus being out can result in differing experiences for transpeople. Connell (2010) and Schilt's (2010) studies are an example of one institution, but can be expanded to include other institutions such as mental health services. Given these findings, I hypothesize that transwomen (MTF) will be more likely to experience discrimination at mental health clinics than transmen (FTM).

Connell (2010) mentioned that many of her participants developed a sense of awareness to gender discrimination through their transitions, and how this affected either gaining access or losing access to power. The discrimination and change of access to power is clearly reflected in Schilt's (2010) findings. These unequal work experiences are sometimes explained due to the culture of gendered organizations (Schilt 2010). Work systems reproduce gender hierarchies rather than being a neutral system that rewards skill and productivity (Schilt 2010). It is embedded within the organizational culture to 
devalue characteristics that are associated as being feminine, as this helps to reproduce the hierarchy (Schilt 2010). These studies reveal that transwomen and transmen's experiences of discrimination are different, where transmen are able to benefit more from gender inequalities than transwomen. However, these studies do not reveal further differences in the transgender community since they focus on transmen and transwomen. Connell's (2010) findings briefly not that some transgender identities, such as genderqueer, attempt to create a hybrid of gender expression and challenge the binary. For this study, I will also include gender nonconforming identities, such as genderqueer, given there is less research on these non-binary identities and it is unknown if they have similar or different experiences from the larger transgender community. Schilt's (2010) findings suggest that there are benefits or penalties not just due to gender, but also for race and education. These findings justify using education and race as control variables in my analyses.

Experiences at work and employment discrimination are important, especially for economic discrimination. Lombardi et al. (2002) used a questionnaire to understand if economic discrimination because of transgender identity had an effect on reporting experiencing a violent incident, i.e. gender violence. According to Lombardi et al. (2002), "gender based violence and discrimination results in an environment in which covert if not overt permission is given to society to 'punish' people for gender transgressions. This gender fundamentalism operates by denying and stigmatizing any form of gender nonconformity, in the same manner heterosexism denigrates nonheterosexual relationships" (91). Gender fundamentalism is institutionalized and a part of a larger social climate, which Lombardi et al. (2002) believe to be the reason for 
economic discrimination and violence that transpeople experience. Over half of transpeople who participated in their questionnaire had experienced some form of harassment or violence (Lombardi et al. 2002).

Lombardi et al. (2002) found that there was a connection between economic discrimination and gender violence. They measured a violent incident as including at least one of the following incidents: assault with a weapon, assault without a weapon, rape, sexual assault, or attempted assault. Economic discrimination was measured as including at least one of the following: being fired, not being hired, demoted, losing promotions, or being unfairly disciplined due to the respondent's transgender identity. For both economic discrimination and violent incidents, they did not ask the respondent who the perpetrators were in each incident, but only asked if an incident occurred. Using logistic regression, Lombardi et al. (2002) found that economic discrimination due to transgender identity ended up being the strongest predictor of transpeople experiencing a violent incident due to their transgender identity (Lombardi et al. 2002). They found that identifying as transgender lead to a greater likelihood of experiencing violence and economic discrimination. Participants who experienced economic discrimination were about five times more likely to experience some form of violence (Lombardi et al. 2002).

Lombardi et al. (2002) note that "workplace discrimination is so rampant that it is the norm among transgendered people, while outside the workplace visibly transgendered people are harassed, intimidated, and assaulted in public places" (Lombardi et al. 2002). Lombardi et al. (2002) believe that future research is needed in order to understand how the lives of transgender people are affected by discrimination and prejudice. Studies such as Schilt (2010), Connell (2010), and Lombardi et al. (2002) provide examples of how 
research has explicitly examined how transpeople experience and interpret discrimination in the workplace and display a need to understand the experiences outside of the workplace. This study draws from workplace studies to help frame and interpret the analysis I conduct in this thesis. Schilt (2010) and Lombardi et al.'s (2002) research suggest race, education, and income are important factors for transpeople experiencing discrimination. Therefore, I will use these factors as control variables in my analyses.

Miller and Grollman's (2015) study goes beyond just the workplace and considers discrimination in a variety of locations, including work and health care settings. Their focus was to look at gender non-conformity, discrimination due to gender identity, and health-harming behaviors. Miller and Grollman (2015) used cross-sectional data from the National Transgender Discrimination survey, the largest survey of self-identified transgender adults in the U.S. Gender nonconformity was measured by using responses to the statement: "People can tell I'm transgender/gender nonconforming even if I don't tell them" (Miller \& Grollman 2015). However, participants who identified as genderqueer and those who did not identify as transgender were excluded from analyses because "their sense of gender identity and expression - namely, their greater emphasis on gender non-conformity - is qualitatively different than those of trans people” (Miller \& Grollman 2015:814). Transphobic discrimination was measured by using major discrimination (fired, not hired, denied health care, etc.) and everyday discrimination (such as harassed or treated unfairly) (Miller \& Grollman 2015).

The majority of trans adults who participated in the National Transgender Discrimination Survey reported experiencing discrimination due to their gender identity (Miller \& Grollman 2015). However, gender nonconforming adults reported more 
transphobic discrimination than transpeople who are gender conforming (Miller \& Grollman 2015). This means that if a transperson visibly appears to be transgender or gender nonconforming then they are at risk for more discrimination (Miller \& Grollman 2015). Gender nonconforming individuals were also more likely to have attempted suicide, drug/alcohol abuse, and smoking (Miller \& Grollman 2015). Miller \& Grollman (2015) argue that their findings highlight how stigma visibility, gender nonconformity in this case, plays a role in minority stress processes. This study draws on Miller and Grollman's research to help justify the inclusion of gender non-conformity and other people's perception of one's gender identity to my analysis to further understand how stigma visibility can heighten discrimination for transpeople. Additionally, I include those participants who identify as genderqueer because their greater emphasis on gender non-conformity can result in different outcomes from individuals who identify as transgender due to their stigma visibility. Given these findings, I hypothesize that transgender and gender non-conforming people who report that others can tell they are trans/gender non-conforming will be more likely to report more discrimination at mental health clinics.

\section{Interactions with the Health Care System}

Previous research regarding transpeople and the health care system has taken two directions: one, the health outcomes of transpeople; and two, their interactions with health care professionals and access to the health care system. Fredriksen-Goldsen et al. (2013) sought to understand the health of transgender older adults, specifically looking to see what are modifiable factors that influence health risks for transpeople and how transpeople compare to nontrans LGB older adults. Modifiable factors included health 
indicators (financial barriers, fear of accessing health services, smoking, etc.), risk factors (internalized stigma, lifetime victimization, and identity concealment), and protective factors (social support, background characteristics, etc.) (Fredriksen-Goldsen et al. 2013). Overall, transgender older adults had a higher risk for poor physical health compared to non-transgender participants (LGB older adults). While modifiable factors such as financial barriers, obesity, and lack of physical activity influenced physical health, risk factors explained the highest proportion of health outcomes for transgender older adults (Fredrikson-Goldsen et al. 2013). Risk factors included lifetime victimization and discrimination, internalized stigma, and identity concealment (Fredrikson-Goldsen et al. 2013). Lifetime victimization and discrimination was measured using a Likert scale where participants were asked how often they experienced different types of victimization due to their actual or perceived sexual/gender identity (physical assault, verbal attacks, being denied or receiving inferior health care, etc.). Internalized stigma was measured by asking participants to rate their agreement to five statements about their feelings about their sexual/gender identity and was made into a summary score ranging from 1 to 4, where higher scores indicated a higher level of internalized stigma. For example, participants were given statements to rank such as "If someone offered me the chance to be completely heterosexual or not transgender, I would accept the chance" (Fredrikson-Goldsen et al. 2013). Identity concealment was measured by asking participants whether people in their life know about their gender or sexual identity, such as family members (mother, father, brothers, sisters, etc.) or best friends.

Fredrikson-Goldsen et al. (2013) found that transgender older adults reported more incidents on average of lifetime victimization and discrimination than 
nontransgender LGB older adults (11 incidents and 6 incidents, respectively). Some of the most commonly reported types of discrimination and victimization transgender participants reported included: verbal insults (76\%), being threatened physical violence (54\%), and being denied or provided inferior health care (40\%) (Fredrikson-Goldsen et al. 2013). Fredrikson-Goldsen et al. (2013) found that the direct effects of gender identity on health outcomes were not significant, but were statistically significant when risk factors were used as a mediating factor. Specifically, "the indirect effects of gender identity on all the health outcomes through internalized stigma and victimization were statistically significant" (Fredrikson-Goldsen et al. 2013:495). While this research considers victimization and discrimination as a mediating factor for health outcomes, it is important to my thesis as it helps to conceptualize victimization and discrimination and reveals that physical assault, verbal attacks, and being denied or receiving inferior health care are important forms of discrimination transgender people face. This study will consider these forms of discrimination.

Interactions with health care professionals help to shape transpeople's experiences with the health care system. Johnson et al. (2008) looked at previous research on the health care issues of the LGBTI (lesbian, gay, bisexual, transgender, and intersex) population from 1993 to 2002 in order to provide a recent-historical perspective on this population's health care and health-related needs. They found that previous research covered topics such as: access to health care, utilization of care, training of providers, and the set up of clinical offices and waiting areas (Johnson et al. 2008). Transpeople face obstacles in trying to access health care, both because they are disproportionately uninsured and because insurance does not cover most health care related to transgender 
issues (Johnson et al. 2008; Sperber et al. 2005). Even for those that are insured, paying for health care that is related to trans issues and not covered by insurance (transitioning, hormones, etc.) is expensive.

Regardless of affordability, quality of care is also a concern when considering if transpeople will seek health care services. Cooks-Daniels (1998) discusses an overview of how LGBT elders' sexual and gender identities may impact their need and willingness to accept assistance from adult protective services, including health care services. CooksDaniels' (1998) discussion is based on personal knowledge and discussions with social workers and not formal research methods to reach her conclusions. Cooks-Daniels (1998) notes that for those that do see a health care professional, many health care professionals are ignorant of the health care needs and concerns of transgender patients (Cooks-Daniels 1998). Transgender patients experience prejudice from health care providers, even sometimes by those who specialize in treating transpeople (Cooks-Daniels 1998). For example, some transpeople may be told by their health care professionals to lie and fabricate a new "life history" in order to qualify for hormones and surgery (CooksDaniels 1998). Health care professional's behavior and sensitivity to transpeople is important. Yet, little is known about the behaviors that are being reported (Kosenko et al. 2013). The intent of the health care professional is unknown and it is also unknown what transpeople would consider as insensitive treatment (Kosenko et al. 2013).

Kosenko et al. (2013) conducted a survey to learn about self-identified transpeople's health care experiences. Overall, mistreatment in health care included issues around gender insensitivity, displays of discomfort, denial of services, substandard care, verbal abuse, and forced care (Kosenko et al. 2013). At least one instance of 
mistreatment in health care was reported by $71 \%$ of the self-identified transgender participants (Kosenko et al. 2013). Transpeople were denied both medical treatments (hormones, referrals for gender reassignment) and providers refused to meet with them (Kosenko et al. 2013). When health professionals did provide services, the services were not up to standard and could include patients being verbally abused through name calling, threats, or insulting comments (Kosenko et al. 2013). Transgender patients also reported that the health professionals appeared to be uncomfortable (fidgeting, staring, avoiding eye contact, etc.), however it is unknown if there were other factors that resulted in this behavior or if it was negative and prejudicial feelings toward the transgender patient that caused this behavior (Kosenko et al. 2013).

Parallel to Kosenko et al.'s (2013) findings, Sperber et al. (2005) found that transpeople report ignorance, insensitivity, and discrimination were the norm for their interactions with the health care system. Sperber et al. (2005) conducted focus groups with self-identified transpeople (adults and youth who identified as male-to-female or female-to-male) in order to understand their experiences with the health care system. Both the FTM and MTF youth focus groups noted that a health care experience was not just about the quality of care from the provider, but also included other interactions with receptionists and other staff (Sperber et al. 2005). Specifically, FTM youth mentioned that they encounter verbal abuse frequently from receptionists, such as laughing or whispering about their gender presentation (Sperber et al. 2005). The FTM youth focus group felt that in general providers do not want to treat FTM youth and this does not make them feel safe or accommodated (Sperber et al. 2005). 
Providers lack knowledge and training necessary to adequately treat trans patients, often deny services to trans patients, and will often refer to trans issues in an unrelated situation (such as broken bone, treating a cold, etc.) (Sperber et al. 2005). These issues can affect a transperson's willingness to seek out medical care, their trust in a medical provider, and how open they are about their identity in their interactions with a provider. Sperber et al. (2005) recommends that future studies focus on the interaction between transpeople and the health care system, specifically qualitative studies and quantitative studies to map health care gaps and include possible variables such as: employment, socioeconomic status, age, and specific health care coverage of transpeople. To address the issue of categorizing transpeople, Sperber et al. (2002) agrees with the statement released in 1999 by the American Public Health Association (APHA) that "urges researchers and health care workers to categorize transgender individuals as maleto-female, female-to-male or other as appropriate, and not conflate them with gay men or lesbians (unless appropriate to an individual's sexual orientation in their preferred gender) as well as acknowledge the variation that exists among trans individuals" (90).

Overall, this research helps to frame the problem for this study, helps to conceptualize transgender identity (and the variation among transpeople) and discrimination, and provides possible variables to consider (such as socioeconomic status, age, etc.). Kosenko et al. (2013) and Sperber et al.'s (2002) studies justify looking at discrimination in a health care setting, such as mental health clinics. Kosenko et al.'s (2013) findings support considering being denied services and verbal abuse as forms of discrimination in a health care setting. Sperber et al.'s (2002) study support looking at differences between people who identify as female-to-male (FTM) and male-to-female 
(MTF). Sperber et al.'s (2002) suggestion to consider socioeconomic status helps to justify using income and education as control variables in the final analyses of this study.

\section{Interactions with the Mental Health System}

Transpeople have a strained relationship with the mental health field for many reasons ranging from a history of pathologization to current issues paralleling problems within the larger health care system, such as problems with access to services and interactions with professionals. Transgender experiences with the mental health system are important, as it is often the gatekeeper for individuals to receive medical treatment (sex reassignment surgery, hormone therapy, etc.). This is because many medical providers will require from a qualified counselor a letter stating that the person is ready for any transition-related care (Grant et al. 2011). While experiences with the mental health system can provide barriers to these medical treatments, the general mental health of transpeople, especially given issues of coming out or discrimination, is also important. Mental health services can also assist in dealing with discrimination, family rejection, or other social aspects of life (Grant et al. 2011).

While the mental health field has the potential to help people, they also have the power to diagnose patients which labels certain behaviors as right or wrong. Gender dysphoria (discomfort with one's gender identity or gender role, which could lead to sex reassignment) was legitimized as a psychiatric condition beginning in 1979 (Institute of Medicine 2011). First, the World Professional Association for Transgender Health (WPATH) created standards and eligibility criteria (evaluation, recommendation by a mental health professional, etc.) in order for transgender persons to access to quality sex assignment procedures (Institute of Medicine 2011). In 2012, WPATH released the 7th 
edition of Standards of Care for the Health of Transsexual, Transgender, and Gender Non-Conforming People, which removed the recommendation for diagnosis (Johnson 2015). However, WPATH's Standards for Care are not mandated, rather, individual health practitioners can choose whether or not they want to use these standards (Johnson 2015).

The Diagnostic and Statistical Manual of Mental Disorders (DSM) contains standards and criteria for disorders created by the American Psychiatric Association. In 1980, the Fourth Edition of the Diagnostic and Statistical Manual of Mental Disorders (DSM-III) introduced a diagnosis for gender dysphoria (Institute of Medicine 2011). This diagnosis eventually evolved into gender identity disorder, which had different criteria for children, adolescents, and adults in the DSM-IV (Institute of Medicine 2011). For almost twenty years, this diagnosis remained in the DSM-IV and was increasingly controversial as it pathologized gender variance.

In 2013, the American Psychiatric Association released the DSM-5, which diagnoses people who identify with a gender different from their gender at birth with gender dysphoria (American Psychiatric Association 2013). This change reflects needing “a diagnostic term that protects [transgender people's] access to care and won't be used against them in social, occupational, or legal areas" (American Psychiatric Association 2013). This change was included so there can be some diagnosis, as insurance coverage requires a diagnosis for individuals to receive medical treatments. Second, the change reflected a change of wording, where "dysphoria" replaced the word "disorder" in order to remove the stigma that the individual is "disordered" (American Psychiatric Association 2013). Johnson (2015) notes that Gender Dysphoria "positions discomfort 
and distress surrounding the incongruence between assigned sex category and gender identity as resulting from a lack of access to medical interventions rather than the social consequences of gender ideology, transphobia, or cissexism" (804). Even with the changes to the DSM, the medical model of transgender identity poses problems for transpeople due to being held to these normative standards of what it means to be transgender (Johnson 2015). These normative standards may be helpful for those transpeople who are interested in medical interventions, but not all transpeople want surgeries or hormone therapy (Johnson 2015). The medical model therefore influences multiple domains of life, including interactions with healthcare, community groups, and the legal system (Johnson 2015). Due to the medical model's power to create normative standards, it can influence members within the transgender community by creating a hierarchy among transpeople where not aligning with the medical model can be interpreted as not being "trans' enough" (Johnson 2015). Additionally, the legal system utilizes the medical model provided by the psychiatric community. This poses problems for transpeople as in order to be legally recognized as male or female, many states will require transpeople to adhere to the medical model where they seek medical interventions (Johnson 2015). Overall, the medicalization of transgender identity influences transpeople's lives and privileges a model that pushes medical interventions on transpeople rather than understanding how gender is social construct that affects individual's experiences and identity.

While criteria, diagnosis, and terms have been controversial and changing, research suggests that health providers are largely unprepared for LGBT clients, specifically transgender people (Eliason et al. 2009). Bryant (2005) discusses a shift in 
clinical practices that attempts to understand and meet the needs of transgender clients. The transgender model, replacing the outdated "transsexual model" that had a goal for sex reassignment, seeks to define gender variance as normal and allows for a wide range of identities (Bryant 2005). This shift in models represents the move from seeing if a patient is ready for sex reassignment to helping the client make sense of their gender identity and any life plans (Bryant 2005).

Diagnoses of gender identity disorder from the DSM-IV have been controversial. While this diagnosis has changed recently, many children have been diagnosed under these criteria and possibly still feel the effects of such a classification. This diagnosis classifies both gender-variant identity and expression as pathological (Institute of Medicine 2011). However, many children with varying gender expressions do not actually identify as transgender in adolescence or adult life (Institute of Medicine 2011). Children's varying gender expressions can lead to identifying with many gender identities later in life, including a binary gender or genderqueer. Research on the mental health of transgender youth is limited, partially due to no available data from national probability samples (Institute of Medicine 2011). Overall, studies have found many transgender youth do not report mental health problems (Institute of Medicine 2011). These results could be due to either not experiencing mental health problems or not being willing to disclose any mental health problems.

Another major finding regarding research on transgender youth is that they are at high risk for suicide and suicide attempts, with more than 50 percent of transgender youth having had a least one-suicide attempt by their $20^{\text {th }}$ birthday (Youth Suicide Prevention Program 2011). While suicide is the third leading cause of death for people ages 10 to 24, 
LGBTQ youth are at higher risk for suicide and suicide attempts (Youth Suicide Prevention Program 2011; Centers for Disease Control and Prevention 2015; Grossman \& D'Augelli 2007). Clements-Nolle et al. (2006) found similar rates of suicide attempts among transgender people and suggested that mental health providers should address forced sex, depression, and substance abuse in order to combat these high suicide attempt rates. In addition, transgender youth report they have inadequate resources to address their mental health concerns and the lack of safe environments (Grossman and D'augelli 2006).

Overall, studies have found that transgender people in early and middle adulthood have negative mental health outcomes (Institute of Medicine 2011). Stress has been associated as a major source for negative mental health for sexual minorities, which includes transgender persons (Institute of Medicine 2011). Stress is considered to be both "felt stigma" and "self-stigma," where they feel both the experience of stigma against their own group (felt stigma) and the acceptance of these negative attitudes associated with them (self-stigma) (Institute of Medicine 2011). Clements-Nolle et al. (2006) notes that research has been done to understand that LGB people are more likely than heterosexual people to attempt suicide, however little is known about transgender adults and suicide attempts. Eliason (2010) reports that previous research has consistently found that sexual and gender minorities have a higher risk for mental health and suicide-related behaviors. However, Eliason (2010) notes that few studies have focused only on transpeople and note that there is growing evidence that says bisexual, questioning, or people exploring their sexuality or gender without a label may be at an even higher risk for suicide than those who identify as lesbian or gay. While this does not provide a 
suggestion as to why these populations may be at higher risk, Eliason's (2010) review of research on LGBT suicide risk notes a shift from previous research focusing on individual risk factors to considering larger social forces such as minority stress.

Minority stress may be a reason that considering other sexual and gender minority populations, such as transpeople or people who do not use a label, is important. Clements-Nolle et al. (2006) interviewed male-to-female (MTF) and female-to-male (FTM) adults in order to understand the predictors of attempted suicide. Attempted suicide was significantly higher for participants who were white, less than 25 years old, recently unemployed, and had been incarcerated (Clements-Nolle et al. 2006). Predictors of attempted suicide included depression, low self-esteem, history of alcohol or drug treatment, forced sex or rape, gender discrimination, verbal gender victimization, and physical gender victimization (Clements-Nolle et al. 2006). Gamarel et al. (2014) conducted a survey of transwomen and their cisgender male partners to understand how trans related discrimination and relationship stigma were associated with relationship quality and mental health. Gamarel et al. (2014) found that transgender related discrimination not only affects transpeople, but their cisgender partners as well. Both partners (transwomen and their cisgender male partners) had an increased odds of depressive distress (Gamarel et al. 2014).

Meyer (2003) argues that LGB people have a higher prevalence of mental disorders than heterosexual people, however minority stress contributes to why this excess is so prevalent. Meyer (2003) theorizes that minority stress (stigma, prejudice, and discrimination) creates an unsupportive social environment that is the cause for mental health problems in LGB populations. Meyer's (2003) theory can be extended to the 
transgender population given their increased experiences of gender discrimination and victimization. Additionally, Meyer's theory of minority stress is used throughout previous research on transpeople and health or mental health (Gamarel et al. 2014; Testa et al. 2012; Balsam et al. 2011; Clements-Nolle et al. 2006; Hendricks \& Testa 2012). Hendricks and Testa (2012) provide a conceptual framework that adapts Meyer's minority stress model to apply to clinical work with transgender and gender nonconforming people. The adapted framework provides a conceptualization of the unique stressors faced by trans clients (Hendricks \& Testa 2012). Unique stressors (such as high levels of physical and sexual violence, expectations of violence and discrimination, internalized transphobia, etc.) affects vulnerability, resilience, and access to and engagement in mental health services (Hendricks \& Testa 2012).

Testa et al. (2012) utilized Hendricks and Testa's (2012) adaptation of Meyer's (2003) minority stress theory to include gender identity and expression. Testa et al. (2012) conducted secondary data analysis in order to understand if physical and sexual violence was related to suicide ideation, suicide attempts, and substance abuse for selfidentified transpeople. Stressful events (such as victimization and discrimination) result in various mental health factors that go beyond reactions that of the general population (people who are not sexual or gender minorities) would have, such as expecting future victimization, internalized homophobia/transphobia, and identity concealment (Meyer 2003; Henricks \& Testa 2012). Transwomen and transmen who reported physical and sexual violence were at a significantly higher risk for suicidal ideation and suicide attempts than transpeople who did not have those violent experiences. This result is consistent with effects for the general population. About half of the participants reported 
experiencing a history of victimization, and there were no statistically significant

differences between transmen and transwomen's experiences (Testa et al. 2012). The key sources of violence included both people close to and far removed from the victim, such as strangers and family members (Testa et al. 2012). Only about 10\% of transgender participants reported the violent incidents to the police, which shows underreporting, fear, and distrust likely due to the fear of secondary discrimination where they are discriminated against by the people who they are seeking help from (Testa et al. 2012). Fear of secondary discrimination was found to be a problem for transgender older adults as well (Fredriksen-Goldsen et al. 2013). Transgender older adults were at high risks of poor health outcomes, both physical and mental, compared to non-transgender people (Fredriksen-Goldsen et al. 2013). This risk is largely due to factors such as fear of accessing health services, internalized stigma, victimization, and lack of social support (Fredriksen-Goldsen et al. 2013). All of these factors reflect barriers in accessing mental health care and reasons why receiving mental health care would be important topic of study for this population. 


\section{METHODS}

In order to best understand the relationship between transgender people and their experiences of discrimination within the mental health field, I used the National Transgender Discrimination Survey (2008). This survey was conducted by the National Center for Transgender Equality and the National Gay and Lesbian Task Force in order to understand the extent of discrimination against transgender and gender non-conforming people. The final sample from this survey included 6,456 respondents $(6,021$ online surveys, 435 paper surveys) from all 50 states, the District of Columbia, Puerto Rico, Guam, and the U.S. Virgin Islands. Surveys were administered both online and through paper surveys, in order to get respondents from hard-to-reach populations (rural, homeless, etc.). Participants were recruited by using convenience sampling techniques, such as venue-based sampling and snowball sampling. Due to this survey using a convenience sample, there is no available information on response rate.

The survey was announced through multiple organizations and communities such as: 800 transgender-led or transgender-serving community based organizations in the U.S., 150 active online community listervs, and 2,000 paper surveys available to organizations that serve hard-to-reach populations (homeless, rural, etc.). Organizations were contacted through phone outreach for three months. Organizations included statelevel and local-level political groups, social groups, support groups, college-based student groups, health organizations, and groups that organized around a particular identity (race or ethnicity, religious affiliation, etc.). However, it is unclear how participants were recruited (scripts, etc.). Surveys were available in both English and Spanish. This was a non-probability sample, as the online survey was fielded through 
transgender-led or transgender-serving community organizations, and data was collected from September 2008 through March 2009. (Grant et al. 2011).

Conducting research on LGBT populations poses challenges such as operationalizing concepts (such as defining transgender) and it is difficult to obtain a large enough sample from a population that represents a small proportion of the larger U.S. population (Institute of Medicine 2011). Therefore, research on LGBT populations commonly uses nonprobability samples (Institute of Medicine 2011). While utilizing nonprobability samples restricts generalizability, they have provided useful information that has expanded LGBT research and more generally provide suggestions of relationships among variables, and generate hypotheses for future research (Institute of Medicine 2011).

\section{Variables}

The independent variables for this study include the following identities: transgender, transsexual, FTM, MTF, gender non-conforming, and genderqueer. There is no common practice for operationalizing transgender (Institute of Medicine 2011). One option is to ask participants if they identify as transgender, and then to ask if they also identify as female to male (FTM) or male to female (MTF) (Institute of Medicine 2011). The NTDS (2008) utilized the options that the Institute of Medicine (2011) suggested and incorporated multiple questions in order to try to fully capture the identities of their participants. The NTDS (2008) chose to ask multiple questions in order to ask participants about their gender identity, including: if the participant considers themselves to be transgender/gender non-conforming in any way; what their primary gender identity is today; and to what degree certain terms applies to the participant (transgender, FTM, 
MTF, gender non-conforming or gender variant, etc.). I also used the independent variable that asked participants if other people are able to tell that they are transgender or gender non-conforming.

The dependent variable is self-perception of discrimination at mental health clinics. The NTDS (2008) operationalized discrimination as including: denied equal treatment or service, verbally harassed or assaulted, and physically attacked or assaulted. Operationalizing discrimination as including these factors is in line with previous research that has found these to be some of the most commonly reported forms of discrimination that transpeople experience (Kosenko et al. 2013; Fredrikson-Goldsen et al. 2013).

For the multivariate analyses, I use three control variables: whether or not someone identifies as white, annual household income, and highest degree. Previous research has found that there are differences in experiences among transpeople due to race, income, and education (Schilt 2010; Lombardi et al. 2002; Sperber et al. 2005). Respondents reported that 83.2 percent identify as white and about half of respondents $(50.2 \%)$ reported that their annual household income was less than $\$ 40,000$. Respondents most commonly reported that their highest education level completed included: bachelor's degree $(27.2 \%)$, some college where they completed more than one year but did not obtain a degree (19.7\%), and master's degree (13.4\%).

\section{Independent Variable}

The NTDS (2008) asked participants multiple questions in order to understand their gender identity. These questions attempted to cover participants' primary identity, the degree participants identified with varying gender non-conforming terms, and others' 
perception of their gender identity. One question that is relevant for this study is: For each term listed, please select to what degree it applies to you (not at all, somewhat, strongly). Chart 1 presents the terms participants were able to select from and their responses.

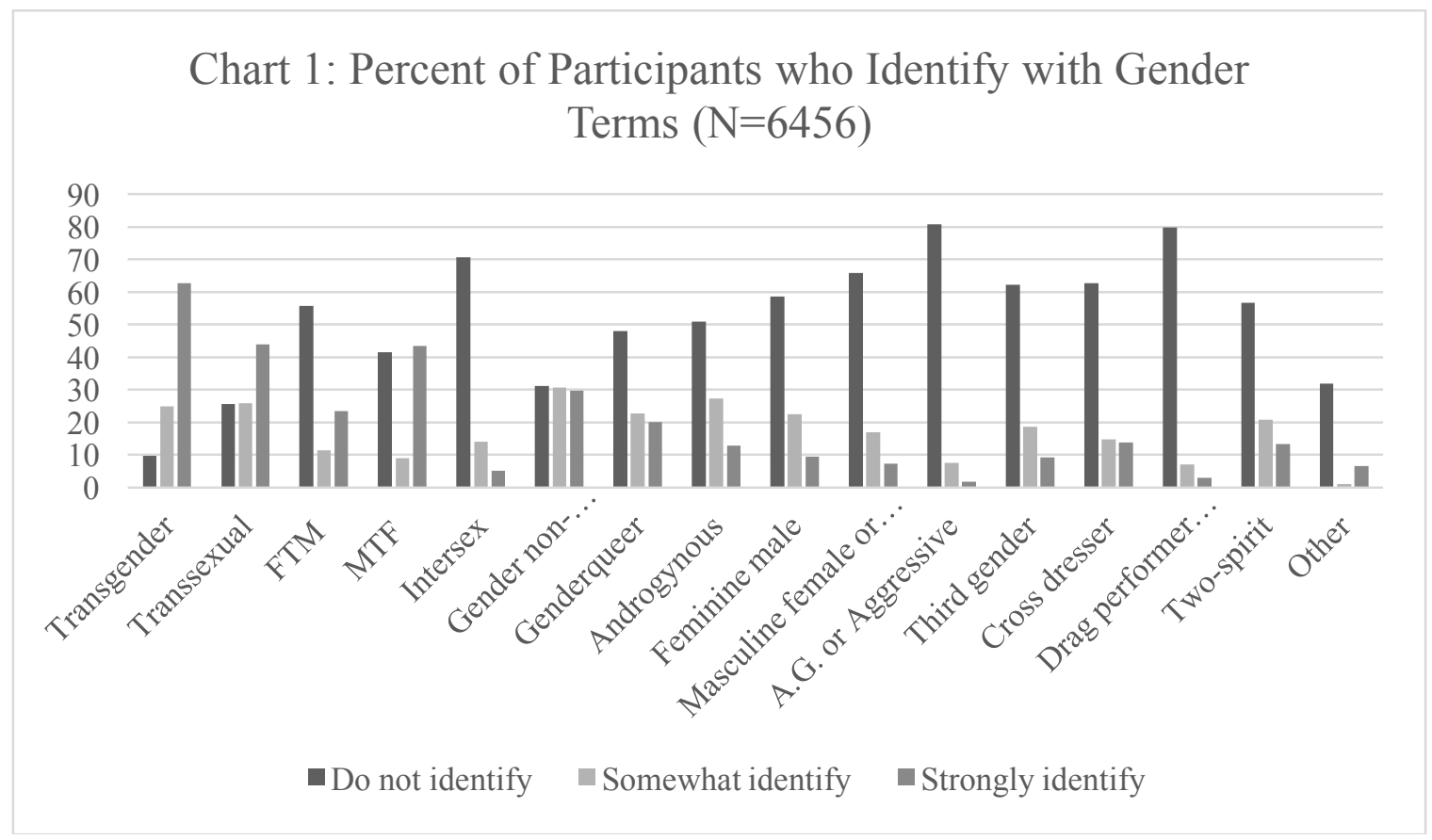

Chart 1 shows that participants most strongly identified with the terms transgender (62.6\%), transsexual (44\%), MTF (43.4\%), gender non-conforming or gender variant (29.6\%), FTM (23.3\%), and genderqueer (20\%). When asked if they identified with other terms, only $60 \%$ of participants responded to the question. Of those $60 \%$ of participants, only $16.8 \%$ strongly identified with a term not provided. Participants were then able to specify other terms not listed, which they identified with terms such as: woman with a trans or transsexual past, woman, transwoman, agender, male, male of transsexual experience, post-operative, or between genders. The terms participants provided reflect terms that are not used as frequently in previous literature (agender, between genders, 
etc.), are reflective of the more recent trends of terminology (transwoman), or participants may identify with their "new" gender as post-operative or post-transition. Therefore, I excluded these identities in analyses.

Due to the survey allowing for multiple ways to identify if a respondent is transgender or gender non-conforming, I analyzed multiple options since there is no standardized approach to operationalizing the identity of being transgender and there is little research on gender non-conforming identities. While previous research has largely focused on people who self-identify as transgender, some previous studies have included gender identities such as genderqueer and gender non-conforming (Schilt 2010; Connell 2010; Miller \& Grollman 2015).

I am not considering all of the identities in Chart 1; I excluded identities that are not focused on in previous research and that participants did not significantly identify with, such as: intersex, androgynous, feminine male, etc. In order to operationalize transgender, I used the Institute of Medicine's (2011) suggestion of considering if people identify with transgender, male to female (MTF), and female to male (FTM) terms. I also considered the transgender and gender non-conforming identities that participants most strongly identified with, including: transsexual, gender non-conforming or gender variant and genderqueer. I did not recode any of these variables for bivariate analyses in order to maintain the degree to which a participant identifies with each term (not at all, somewhat, or strongly). For multivariate analyses, I only considered the differences between participants who strongly identified as FTM or MTF. I excluded all other identities from the analyses and recoded the variables FTM and MTF into dichotomous variables ( $1=$ always identify, $0=$ do not always identify). 
Additionally, each identity is not mutually exclusive. Participants were asked to select a degree to which they identified will all terms provided in Chart 1. For example, a participant can strongly identify as transgender, somewhat identify as FTM, and not at all identify with the term genderqueer. Table 1 presents the percentages of respondents who identify with each of these terms, and to what degree (not at all, somewhat, or strongly).

Table 1: Percent of Respondents' Identities

\begin{tabular}{lcccccc}
\hline & Transgender & Transsexual & $\begin{array}{l}\text { FTM } \\
\text { (female } \\
\text { to } \\
\text { male) }\end{array}$ & $\begin{array}{l}\text { MTF } \\
\text { (male to } \\
\text { female) }\end{array}$ & $\begin{array}{l}\text { GNC/Gender } \\
\text { Variant }\end{array}$ & Genderqueer \\
\hline Not At All & 9.9 & 26.8 & 61.6 & 44.1 & 34.1 & \\
Somewhat & 25.6 & 27.1 & 12.6 & 9.6 & 33.6 & 25.0 \\
Strongly & 64.5 & 46.1 & 25.7 & 46.2 & 32.4 & 22 \\
Total & $\mathrm{N}=6258$ & $\mathrm{~N}=6154$ & $\mathrm{~N}=5835$ & $\mathrm{~N}=6066$ & $\mathrm{~N}=5903$ & $\mathrm{~N}=5865$ \\
\hline
\end{tabular}

Over half of respondents (64.5\%) strongly identified as being transgender. In addition, over half of respondents did not identify as female to male $(61.6 \%)$ or genderqueer (53.0\%). While these percentages show what terms participants did not identify with, they are significant due to the complexity of terms used to describe nonbinary gender identities. Identification with being male to female was more divided, with 44.1 percent of respondents not identifying and 46.2 percent of respondents strongly identifying as male to female. Transsexual is a term that has been historically used to describe a person who transitions from one gender to another, but in more recent years has been less popular with younger generations. However, 46.1 percent of respondents reported that they strongly identified with this term. This may be due to the survey targeting all transgender and gender non-conforming people, regardless of age, allowing for the possibility that older generations who still identify as transsexual may have taken the survey. The original survey did not ask participants any question regarding their 
current age, but rather asked participants the age they first recognized their transgender/gender non-conforming identity, and when they started to live as transgender (part time, full time), and first time they got any trans-related medical care. Because the age at which participants took the survey is unknown, it is not possible to know how their age affects their self-identification or experiences of discrimination. Gender nonconforming, gender variant, and genderqueer are terms that have been more popular in recent decades. Data shows that 32.4 percent of respondents strongly identified as gender non-conforming or gender variant, and 22 percent of respondents strongly identified as genderqueer.

While these are the identities respondents' most strongly identified with, not all people who took the survey answered all parts of the question. This is evident through the variation in $\mathrm{N}$ for each identity in Table 1 . Respondents may have refused to answer parts of the question because they did not understand the term, such as they had not heard the new/old term or they may not understand what the term means so they are unsure if they identify with the term. Additionally, the survey allowed for respondents to strongly identify with more than one term, which means participants may strongly identify with multiple identities (transgender and genderqueer, etc.).

It is important to consider all of these categories, as people can have varying reasons as to why they identify with different terms and not others. For example, a respondent could identify strongly with the term transgender but not as FTM or MTF. This could be due to identifying with being transgender as an overall term for being gender non-conforming, but not going through the process or not planning to go through the process of changing their body to the opposite sex (hormone therapy, etc.). There are 
also possible age differences with terms, such as older generations who used the term transsexual but later generations created the term transgender, and in more recent decades there has been a shift to terms that imply gender fluidity such as gender non-conforming, gender variant, and genderqueer.

However, an individual specifying their own identity is only one part of the story. In order to gain a more comprehensive understanding of transpeople's experiences, I took into consideration Miller and Grollman's (2015) suggestion that gender nonconformity can be a visible marker of a stigmatized status which can increase transpeople's experiences with discrimination. Participants were asked in the survey to select to what degree they agreed with the following statement: People can tell I'm transgender/gender non-conforming even if I don't tell them. Chart 2 shows respondents' answer to this statement.

\section{Chart 2: Other People's Perception of Respondents' Gender}

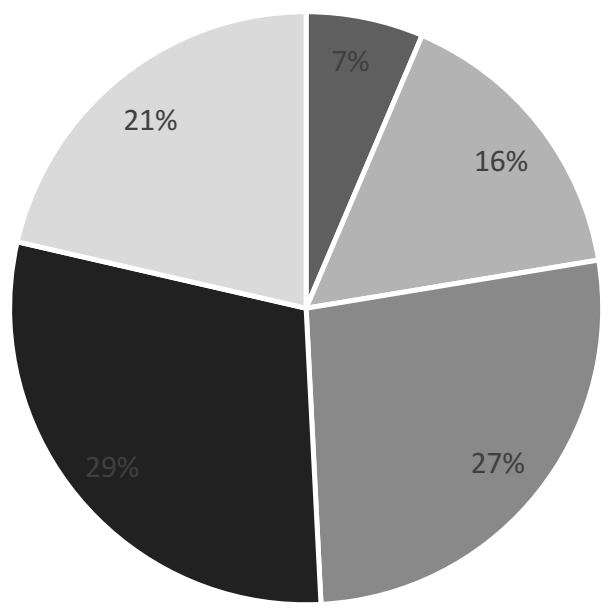

- Always

- Most of the time

- Sometimes

- Occasionally

- Never 
Chart 2 shows that only $27 \%$ of respondents reported that other people never are able to tell that they are transgender/gender non-conforming. This means that for $73 \%$ of respondents, other people are able to tell that they are trans/gender non-conforming, at least some of the time. This question does not reveal when, where, or how other people are able to recognize that certain participants are transgender or gender non-conforming. It is also unclear why participants believe that others are able to recognize their gender identity. Other people may be able to recognize participants' gender identity for reasons such as location (events/places specifically aimed for LGBTQ people), self-identification (participants reveal their identity), or ambiguity (not presenting clearly within the binary). Due to the varying identities and the importance of other people's perception of one's gender identity, I considered both self-identification and respondent's reports of other people's perception of their gender identity.

\section{Dependent Variable}

My dependent variable is perceived discrimination at mental health clinics. The National Transgender Discrimination Survey surveyed respondents in order to measure discrimination. Participants were asked to answer the following question: Based on being transgender/gender non-conforming, please check whether you have experienced any of the following in these public spaces (Mark all that apply). For each location provided in the question, participants were asked to mark if they had: been denied equal treatment or service, verbally harassed or disrespected, physically attacked or assaulted, not applicable I have not tried to access this, not applicable I do not present as transgender here, or not applicable I did not experience negative outcomes. I excluded the responses "not applicable I have not tried to access this" and "not applicable I do not present as 
transgender here," making the final analytic sample $\mathrm{N}=3370$. This is because I am only considering participants who tried to access mental health clinics. I excluded the responses of those who do not present as transgender here because this is better understood through another question where participants were asked in the survey (if others can tell they are transgender or gender non-conforming) because the other question clearly states if the participant believes that other people perceive them to be transgender or gender non-conforming.

Due to the survey providing definitions of discrimination at mental health clinics, I did not recode any of these variables. However, the limitation to operationalizing discrimination as being denied equal treatment or service, verbally harassed or disrespected, and being physically attacked or assaulted is that this may not be a fully comprehensive way to define discrimination. For example, respondents could have also felt that discrimination took place during a session. This discrimination could have been where they felt the counselor or therapist treated them differently than other patients, but was still given services and it did not qualify as a verbal or physical attack.

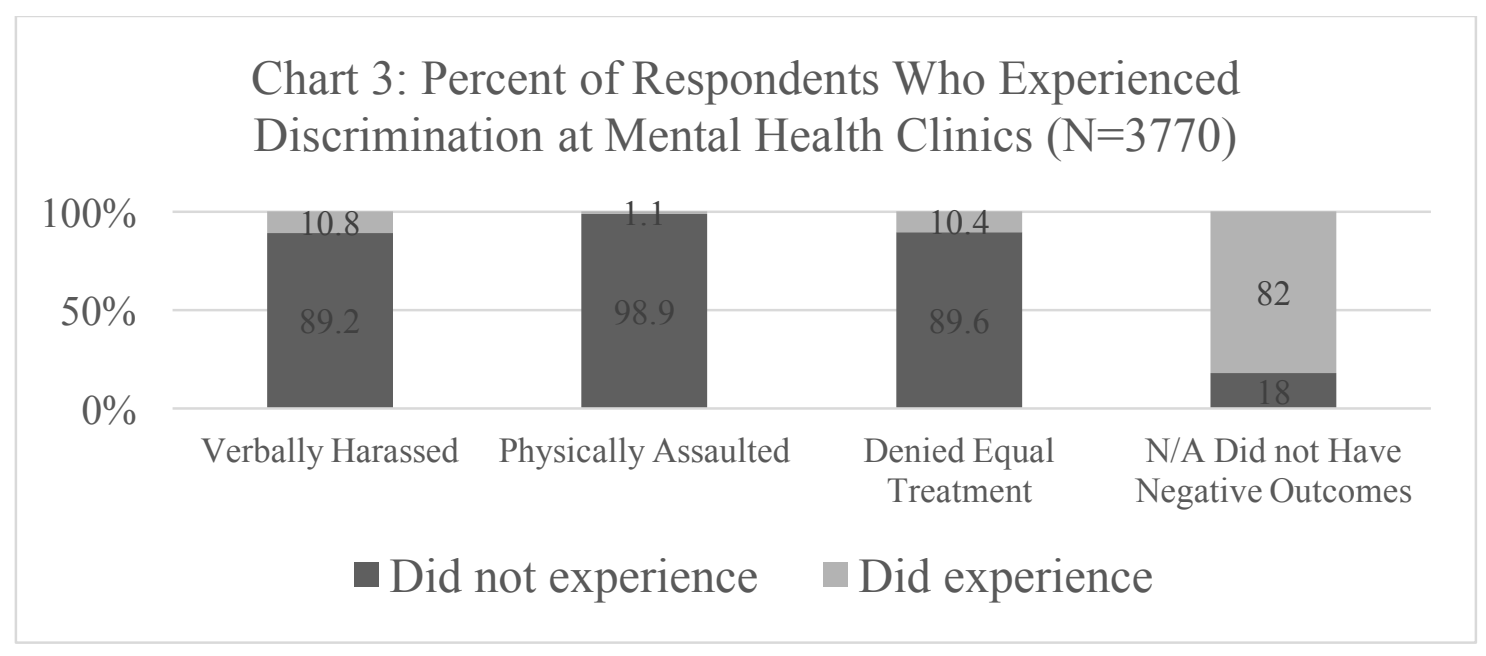


Chart 3 reveals that participants most commonly reported that they did not experience these negative outcomes (82\%). Participants reported experiencing being verbally harassed or disrespected (10.8\%) and being denied equal treatment or services $(10.4 \%)$ more than being physically attacked or assaulted (1.1\%). However, the responses to this question included all participants of the survey, including those with identities that I am not specifically including in my study (two-spirit, intersex, androgynous, etc.). It is possible that the percentages of those who experienced discrimination at mental health clinics are higher for those identities that I am including in my study. 


\section{RESULTS}

I conducted bivariate analyses in order to understand the following associations:

1. Gender identity and how others perceive their gender identity

2. Gender identity and form of discrimination

3. Others' perception of their gender identity and form of discrimination.

Following these bivariate analyses, I conducted logistic regression analyses in order to understand if others people's perception of their gender identity was a significant predictor for each form of discrimination. I also conducted a series of logistic regressions in order to understand if strongly identifying as MTF or FTM was a predictor for each form of discrimination. For each logistic regression, I considered race, income, and education as control variables.

\section{Bivariate Analyses of Identity by Perception of Trans Identity}

I ran a series of cross tabulations in order to understand the association between an individual's self-reported gender identity and their reports of how others perceive their transgender or gender non-conforming identity. Chart 4 provides a bivariate analysis of respondents' transgender identity and if others' can tell that they are trans or gender nonconforming. 


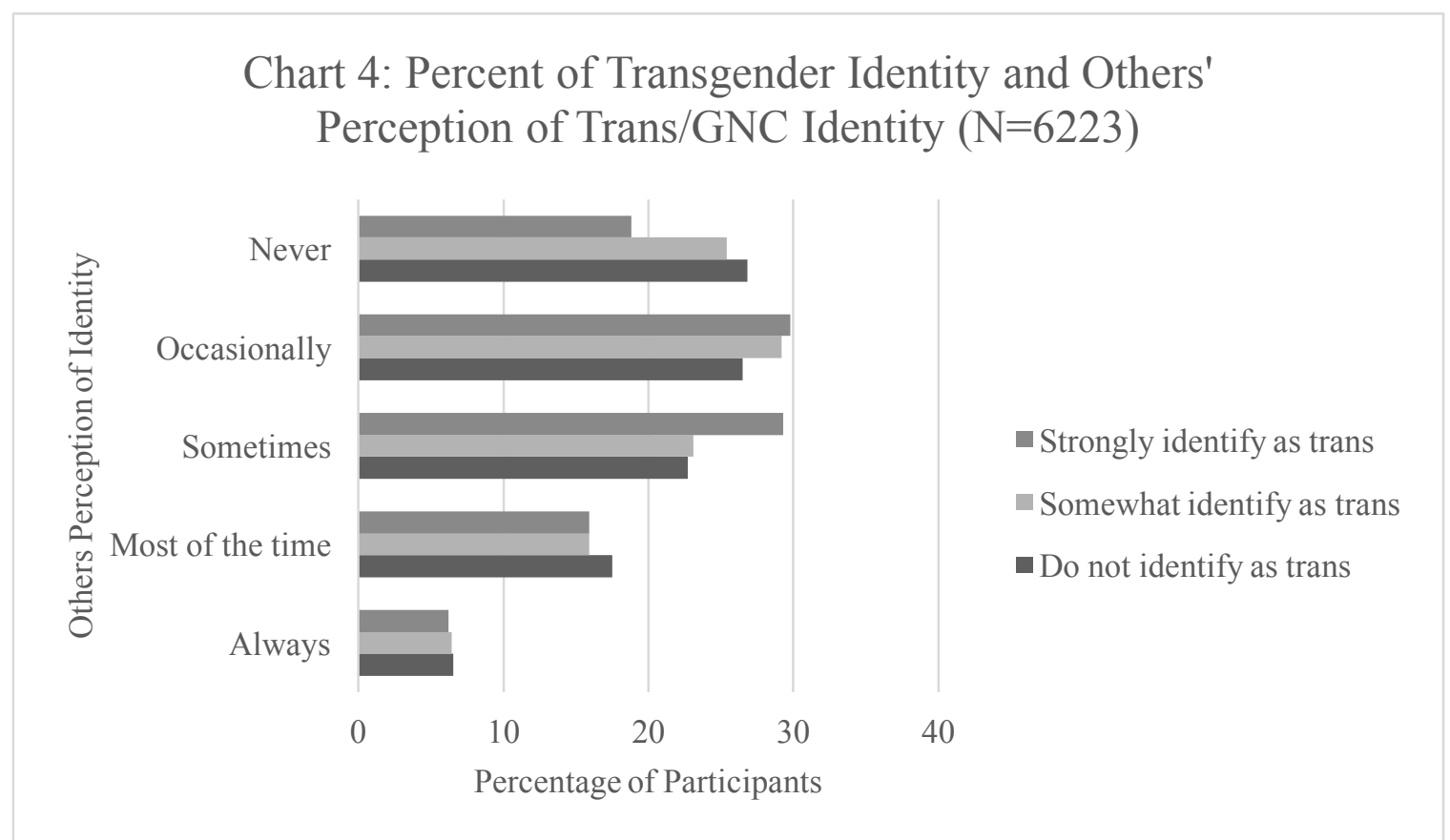

Chi-square $=56.149(\mathrm{p}=0.0)$

Chart 4 shows that participants who strongly identify with the term transgender report that others are able to sometimes $(29.3 \%)$ or occasionally $(29.8 \%)$ tell that they are transgender. In contrast, respondents who reported that others are able to tell they are transgender or gender non-conforming most of the time report that they do not identify with the term transgender. This means that those individuals identify with another term, possibly terms that imply more gender fluidity, such as genderqueer, which could result in more ambiguity or gender confusion for others' perceptions. Respondents who report that others are always able to tell they are transgender or gender non-conforming report roughly the same degree of how much they identify with the term transgender (strongly, somewhat, not at all). This means that regardless of the strength of identifying with the term, this group of respondents believe that others always can tell they are transgender or gender non-conforming. This could be due to age, such as younger generations more often using the term transgender to describe being non-binary but it does not necessarily 
always mean that they intend to change their bodies or gender expression to conform to the opposite gender.

Cross tabulations for each identity yielded similar results. Each bivariate analysis was statistically significant for the following identities: transsexual (Chi-square=194.669, $\mathrm{p}=0.0)$, FTM $($ Chi-square $=250.790, \mathrm{p}=0.0)$, MTF $($ Chi-square $=125.104,0.0)$, gender nonconforming or gender variant (Chi-square $=582.517, \mathrm{p}=0.0$ ), and genderqueer (Chisquare $=611.868, \mathrm{p}=0.0$ ). However, for persons who strongly identify with each of these identities there is variation in the degree to which they report other people can tell they are transgender or gender non-conforming. Persons who report others are occasionally able to tell they are transgender or gender non-conforming report that they strongly identify as transsexual (34.3\%) or MTF (33.8\%). Participants who report that they do not identify with the term MTF reported that others are able to tell they are transgender most of the time (19.2\%) or always (7.9\%). In contrast, participants who strongly identify as FTM report that others can never (32.4\%) tell they are transgender or gender nonconforming. Participants who sometimes identify as FTM report that others are able to tell they are transgender or gender non-conforming most of the time (26.8\%) or always (11.2\%). These results may be due to differences among age cohorts, preference of certain terms over others, and there may be a variation of gender expression (such as preferences for hormones, surgeries, etc.). For example, the term transsexual was more popular in previous decades, but in more recent years there has been a shift for younger cohorts to prefer terms such as transgender or genderqueer. For terms such as FTM or MTF, it is possible that some participants may prefer more recent terms such as transman or transwoman and do not identify as FTM or MTF. Participants who strongly identify as 
MTF reporting that others are occasionally or sometimes able to tell they are transgender or gender non-conforming could be in line with previous literature that has found transwomen's experiences to be different from transmen's in that they experience more discrimination.

Participants who strongly identified as gender non-conforming or genderqueer reported different results from the other identities analyzed. Participants who strongly identified as gender non-conforming or gender variant report that others can always (11.2\%), most of the time (27.2\%), or sometimes (29.1\%) tell that they are transgender or gender non-conforming. In contrast, participants who never identify as gender nonconforming or gender variant report that others can never (30.6\%) tell they are transgender or gender non-conforming. Chart 5 provides a bivariate analysis of respondents' genderqueer identity and if others' can tell that they are trans or gender nonconforming.

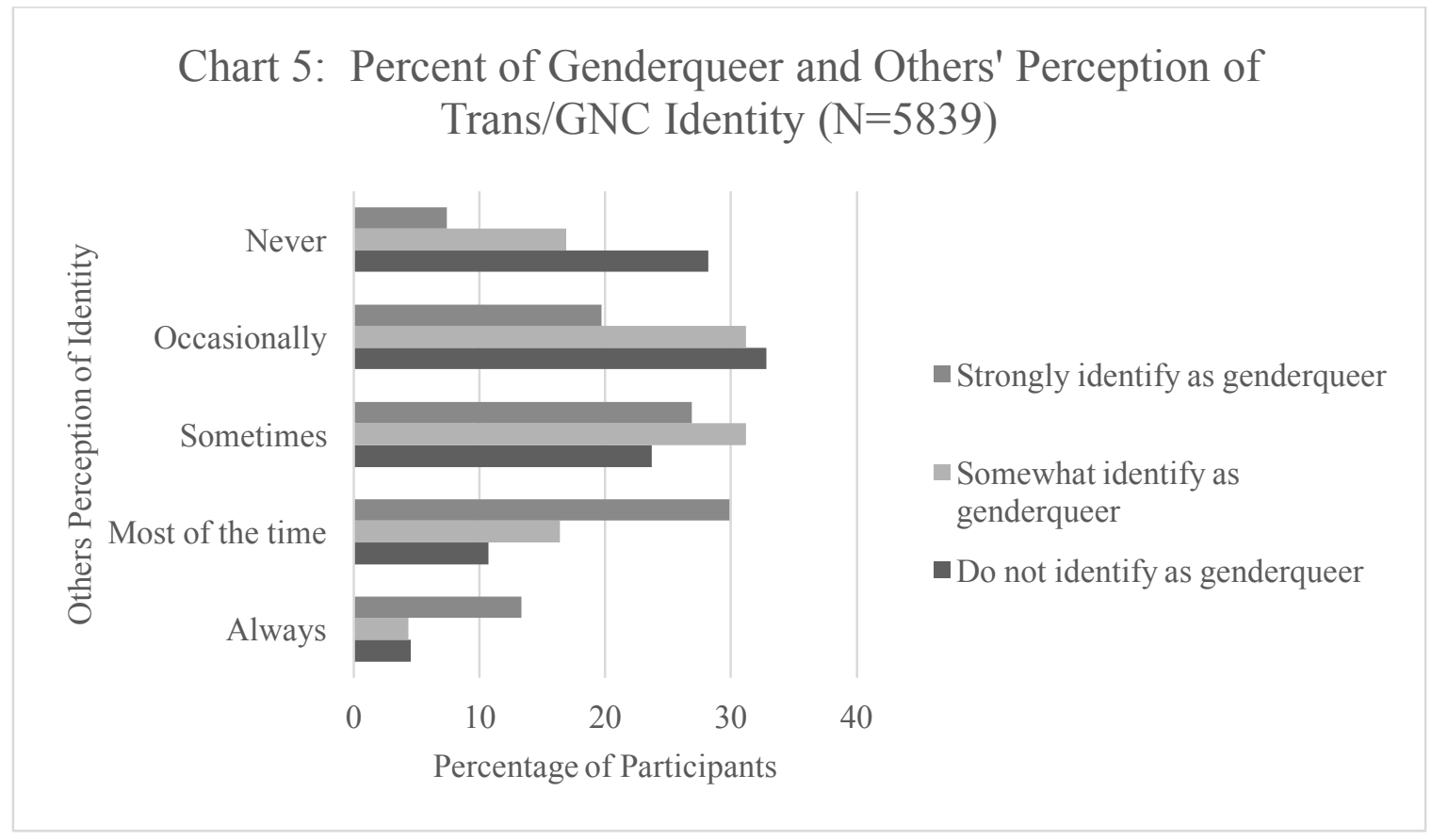


Chart 5 shows that participants who strongly identify with the term genderqueer report that others can always $(13.3 \%)$, most of the time $(29.9 \%)$, or sometimes $(29.6 \%)$ tell that they are transgender or gender non-conforming. Similar to those who do not identify as gender non-conforming, participants who do not identify as genderqueer report that others can never $(28.2 \%)$ or occasionally $(32.8 \%)$ tell they are transgender or gender non-conforming. The results of those who strongly identify as gender nonconforming or genderqueer are distinct from those who identify as transgender, transsexual, FTM, or MTF in that they report that others are able to tell they are trans or gender non-conforming more than those who strongly identify with other identities. This may be due to the terms gender non-conforming and genderqueer being less defined and implying more fluidity and variety of gender expressions, making it possible that those who identify with these terms may also express themselves in a way that does not fit the binary or is more ambiguous. This could also explain why those who do not identify with the terms gender non-conforming or genderqueer report that others are never able to tell they are transgender or gender non-conforming. Preferences for terms could be another explanation, as there are differences among age cohorts within the transgender community. For example, the term genderqueer emerged over the past few decades, which could mean that older generation are less likely to identify with these new terms. The findings from each of these analyses are limited in that they are the respondent's perception of how others perceive them. Therefore, this may or may not be what is actually taking place from other people's point of view. The location that these perceptions are taking place is also unknown, such as at a hospital, LGBTQ meet-up group, or other public spaces. The location could either explain why another person is 
able to tell if someone is transgender or gender non-conforming, such as LGBTQ meetups or events. In contrast, locations such as hospitals or mental health clinics can be based on assumptions or a person having access to information on an individual's gender identity (such as medical charts). It is also unclear how an individual knows that other's can tell they are transgender or gender non-conforming, such as if another person revealed this (making derogatory comments, talking about their identity, etc.) or if the individual is self-conscious of their gender expression.

\section{Bivariate Analyses of Identity by Discrimination}

I performed a series of cross tabulations in order to understand the relationship between transgender, transsexual, FTM, MTF, gender non-conforming, and genderqueer identities and perceived discrimination at mental health clinics. I also performed cross tabulations on other people's perception of respondent's trans or GNC status and their perceived discrimination at mental health clinics. Discrimination was operationalized as including: denied equal treatment or service, verbally harassed or disrespected, and being physically attacked or assaulted. Chart 6 illustrates the results from a series of cross tabulations that show the percent of respondents who were denied equal treatment at 
mental health clinics.

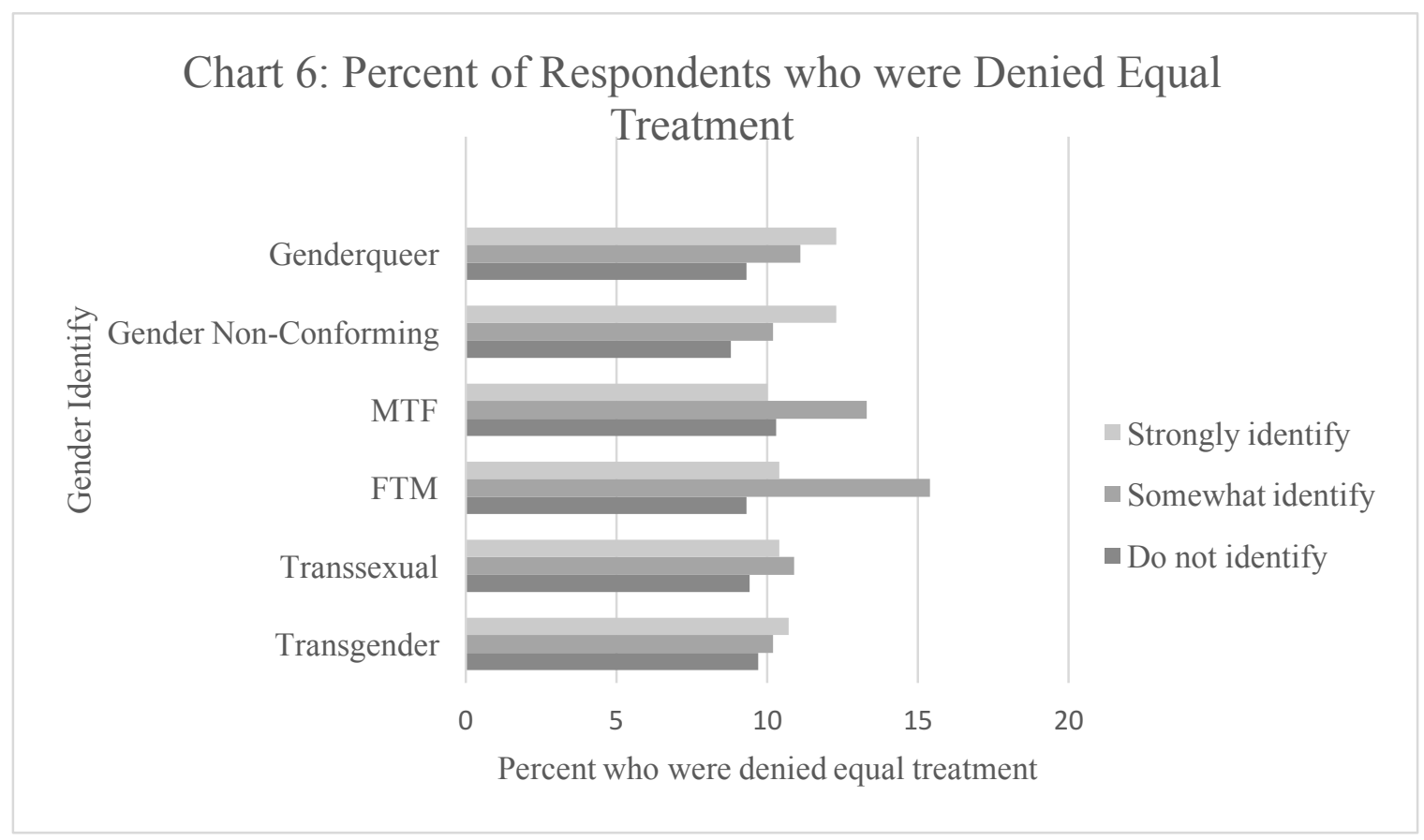

Crosstab results, shown in Chart 6 , suggest that only female to male (Chi-square= 13.957, $\mathrm{p}=0.001)$ and gender non-conforming $($ Chi-square $=7.925, \mathrm{p}=0.019)$ persons report statistically significantly different experiences of being denied equal treatment or services at mental health clinics, compared to those who do not identify as FTM or gender non-conforming. In contrast, the variables transgender, transsexual, MTF, gender non-conforming, and genderqueer, are not statistically significant.

I conducted a cross tabulation of respondents who were denied services and if other people can tell that they are transgender or gender non-conforming. In order to best understand this, I recoded the variable on other people's perception of the respondents' gender identity into a dummy variable, where 1 is when other people can always tell that they are trans or gender non-conforming and 0 is all other responses (most of the time, sometimes, occasionally, and never). I chose to compare that other people can always tell 
to those where others can not always tell they are trans or gender non-conforming because always implies that this does not change, regardless of location. Other people not always being able to tell they are transgender or gender non-conforming may be due to many factors, including location. Therefore, if others can always tell they are transgender or gender non-conforming, this should include at mental health clinics as well. Table 2 considers the percent of respondents who were denied services and if other people can tell if they are transgender or gender nonconforming.

\section{Table 2: Percent of Respondents Who Were Denied Services at Mental Health Clinics}

\begin{tabular}{lll}
\hline $\begin{array}{l}\text { Form of } \\
\text { Discrimination }\end{array}$ & \multicolumn{2}{c}{ People can tell they are trans/GNC } \\
\hline & Always & Not always \\
\hline No & 86.4 & 89.8 \\
\hline Yes & 13.6 & 10.2 \\
\hline Chi-Square & $2.918(0.088)$ & \\
\hline Number of Cases & 258 & 3491 \\
\hline
\end{tabular}

Table 2 reveals that other people's perception of their transgender or gender nonconforming status is not statistically significant for being denied services $(p=0.088)$. Respondents who report that others can always tell they are transgender or gender nonconforming report being denied services more than respondents who report that others can not always can tell they are transgender or gender non-conforming (13.6 percent and 10.2 percent, respectively). Chart 7 illustrates the results from a series of cross tabulations that show the percent of respondents who were verbally harassed at mental health clinics. 


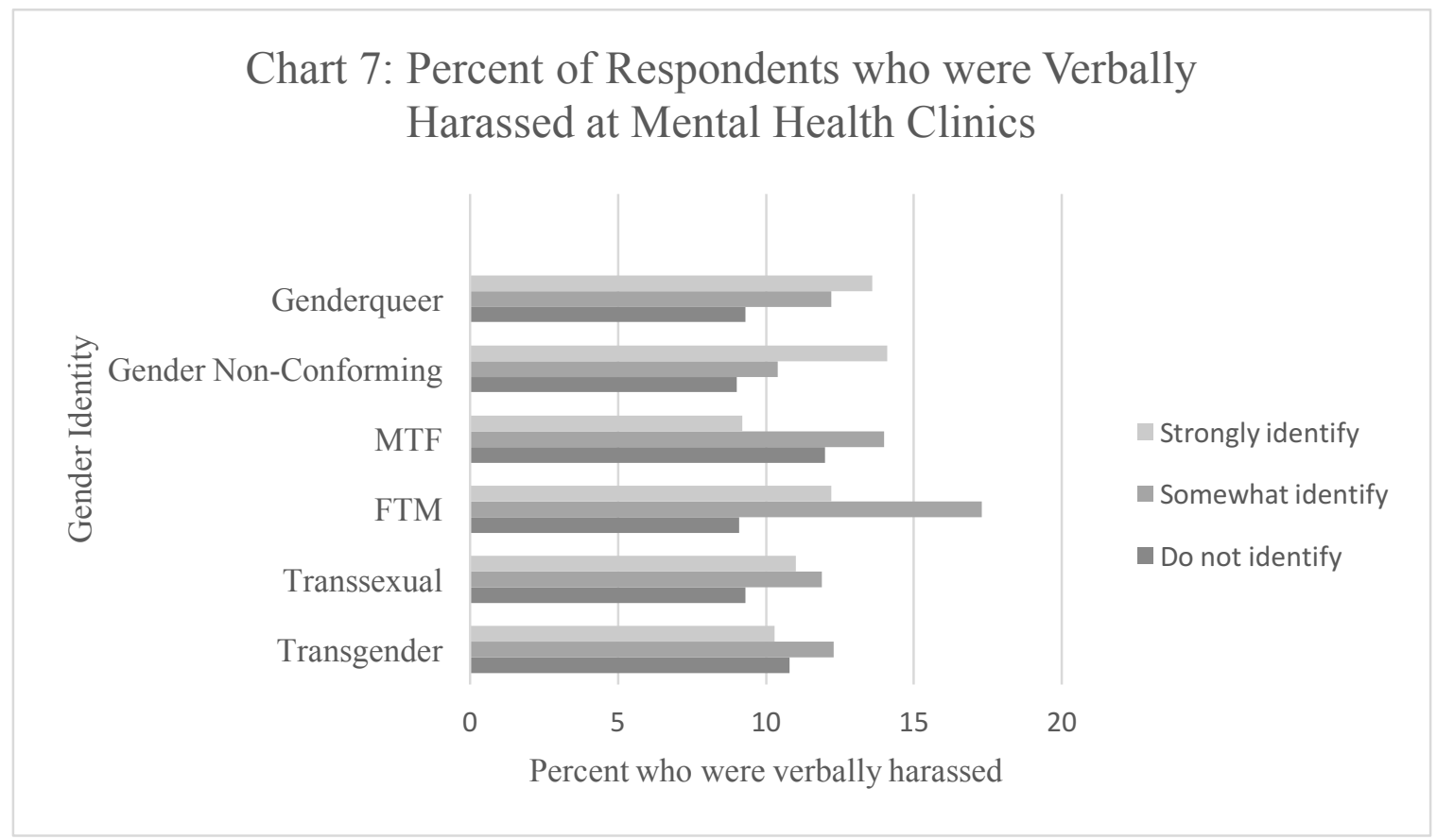

Chart 7 shows that people who identify as female-to-male (chi-square $=25.721$, $\mathrm{p}=0.000$ ), male to female (chi-square $=10.076, \mathrm{p}=0.006$ ), gender non-conforming (chisquare $=15.480, p=0.000)$, and genderqueer $($ chi-square $=11.532, p=0.003)$ have significantly different experiences of being verbally harassed at mental health clinics. In contrast, the variables transgender and transsexual had non-statistically significant results $(p=0.241$ and $p=0.183$, respectively). Table 3 shows the cross tabulation of respondents who were verbally harassed at mental health clinics and their reports of if other people can tell they are trans or GNC.

\section{Table 3: Percent of Respondents Who Were Verbally Harassed at Mental} Health Clinics

\begin{tabular}{lll}
\hline $\begin{array}{l}\text { Form of } \\
\text { Discrimination }\end{array}$ & People can tell they are trans/GNC & \\
\hline & Always & Not always \\
\hline No & 89.5 & 89.2 \\
\hline Yes & 10.5 & 10.8 \\
\hline Chi-Square & $0.033(0.856)$ & 3491 \\
\hline Number of Cases & 258 & \\
\hline
\end{tabular}


Table 3 reveals that other people's perception of their trans or gender nonconforming status is not statistically significant. These results might be nonstatistically significant because it is unknown if respondents' perception of how others perceive them is correct and because it is unknown who is denying them services. Chart 8 illustrates results from a series of cross tabulations that show the percent of respondents who were physically assaulted at mental health clinics.

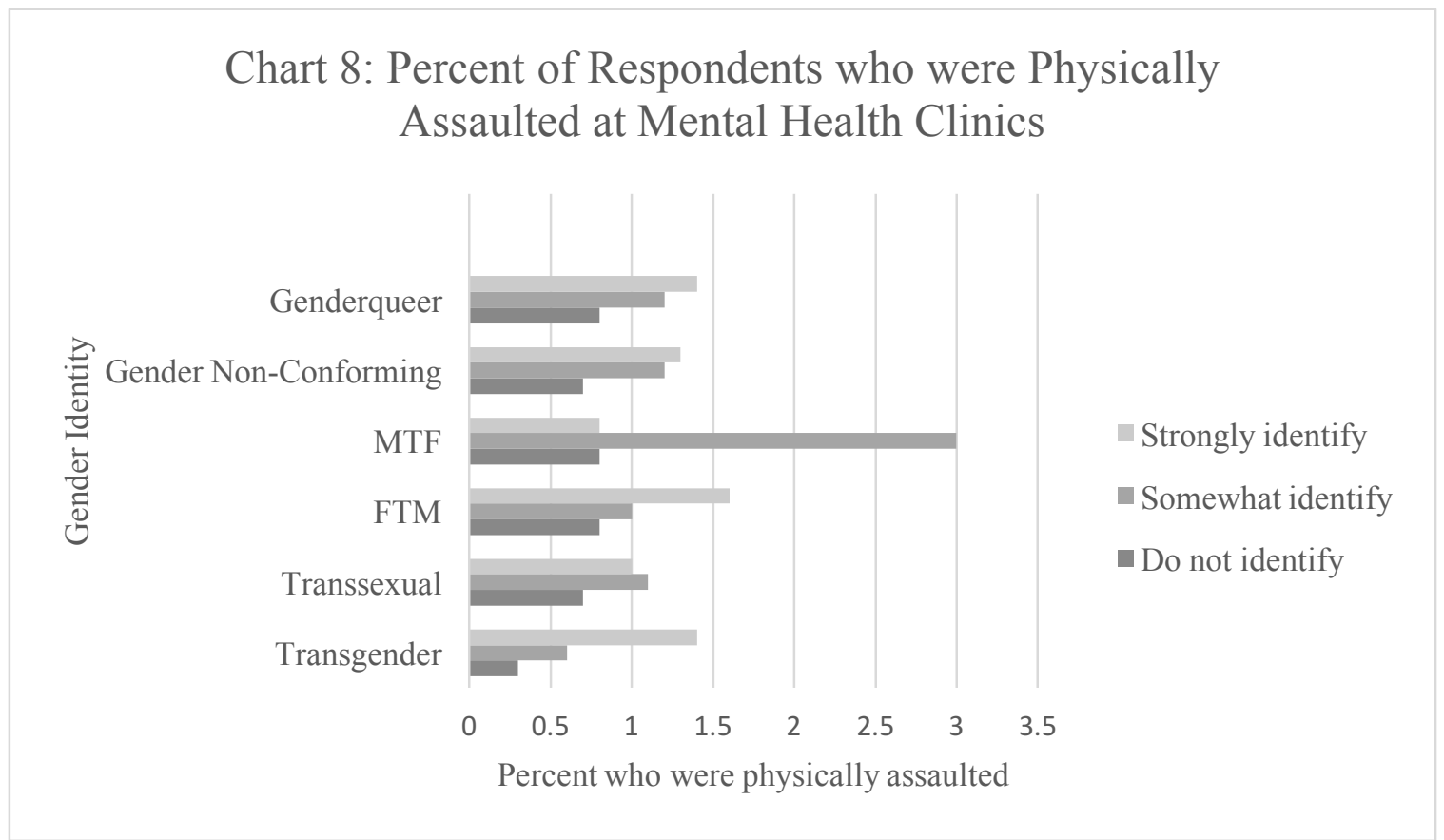

Chart 8 suggests that there are significant results for respondents identifying as transgender $($ Chi-square $=6.929, \mathrm{p}=0.031)$ or male-to-female $($ Chi-square $=12.710$, $\mathrm{p}=0.002$ ) and experiencing being physically assaulted at mental health clinics.

Table 4: Percent of Respondents Who Were Physically Assaulted at Mental Health Clinics

\begin{tabular}{lll}
\hline $\begin{array}{l}\text { Form of } \\
\text { Discrimination }\end{array}$ & People can tell they are trans/GNC & \\
\hline & Always & Not always \\
\hline No & 97.7 & 99.1 \\
\hline Yes & 2.3 & 0.9 \\
\hline
\end{tabular}




Chi-Square $5.431(0.020)$

\begin{tabular}{lll}
\hline Number of Cases & 258 & 3491 \\
\hline
\end{tabular}

Table 4 shows there are significant results for respondents' reports of how others perceive their gender conformity and being physically assaulted at mental health clinics $(\mathrm{p}=0.020)$. Respondents who report that others are always able to tell they are transgender or gender non-conforming are more likely to experience being physically assaulted at mental health clinics than respondents who report that others are not always able to tell they are transgender or gender non-conforming.

\section{Multivariate Analyses}

I used logistic regression models to analyze the likelihood of discrimination in mental health clinics. In all tables, I present the coefficients and standard errors and interpret the odds ratios in the discussion of the results rather than presenting them in the table.

Table 5: Logistic Regression Coefficients Predicting Being Denied Equal Treatment ( $1=$ denied equal treatment; $0=$ not denied equal treatment)

\begin{tabular}{|c|c|c|c|c|}
\hline & Model 1 & & & \\
\hline & $\mathrm{B}$ & S.E. & $\mathrm{B}$ & S.E. \\
\hline (Constant) & $-2.175^{* *}$ & 0.056 & $-1.641 * *$ & 0.193 \\
\hline Others' Perception & 0.324 & 0.190 & 0.221 & 0.198 \\
\hline Annual Household Income & & & $-0.105 * *$ & 0.019 \\
\hline Highest Degree & & & 0.006 & 0.026 \\
\hline $\begin{array}{l}\text { Race ( } 1=\text { white; } 0=\text { not } \\
\text { white) }\end{array}$ & & & -0.089 & 0.142 \\
\hline $\mathrm{N}$ & 3749 & & 3663 & \\
\hline
\end{tabular}

Table 5 results suggest that other people's perception of the respondent's gender (if they present as transgender or gender non-conforming) is not a statistically significant 
predictor in a bivariate model (Model 1). Others' perception is measured as $1=$ always able to tell they are transgender or gender non-conforming, and $0=$ not always able to tell they are transgender or gender non-conforming. Model 2 add gross annual household income (in dollars), the respondent's highest education level completed, and whether or not they identify as white. Model 2 reveals that once income, education, and race are controlled, others' perception of the respondents' gender is still not a significant predictor. Instead, gross annual household income is a statistically significant indicator. Persons with a higher annual household income are 0.900 as likely $(\operatorname{Exp}(-.105)=.900)$ as persons with lower income to experience being denied equal treatment or services at mental health clinics.

Table 6: Logistic Regression Coefficients Predicting Being Verbally Harassed ( $1=$ verbally harassed; $0=$ not verbally harassed) $(\mathrm{N}=6415)$

\begin{tabular}{|c|c|c|c|c|}
\hline & Model 1 & & & \\
\hline & B & S.E. & $\mathrm{B}$ & S.E. \\
\hline (Constant) & $-2.108^{* *}$ & 0.054 & $-1.578^{* *}$ & 0.191 \\
\hline Others' Perception & -0.038 & 0.211 & -0.132 & 0.217 \\
\hline Annual Household Income & & & $-0.128^{* *}$ & 0.019 \\
\hline Highest Degree & & & 0.030 & 0.026 \\
\hline $\begin{array}{l}\text { Race ( } 1=\text { white; } 0=\text { not } \\
\text { white) }\end{array}$ & & & -0.163 & 0.138 \\
\hline $\mathrm{N}$ & 3749 & & 3663 & \\
\hline
\end{tabular}

Table 6 results suggest that other people's perception of the respondents' gender is not a significant predictor for being verbally harassed at mental health clinics. Model 2 adds gross annual household income (in dollars), the respondent's highest education level completed, and whether or not they identify as white. Model 2 reveals that gross annual household income is a statistically significant indicator. Persons with a higher annual 
household income are $0.879(\operatorname{Exp}(-.128)=.879)$ as likely as persons with lower income to experience being verbally harassed at mental health clinics.

Table 7: Logistic Regression Coefficients Predicting Being Physically Assaulted (1=physically assaulted; $0=$ not physically assaulted) $(\mathrm{N}=6415)$

\begin{tabular}{|c|c|c|c|c|}
\hline & Model 1 & & & \\
\hline & B & S.E. & $\mathrm{B}$ & S.E. \\
\hline (Constant) & $-4.748 * *$ & 0.183 & $-3.201 * *$ & 0.521 \\
\hline Others' Perception & $1.010^{*}$ & 0.452 & 0.346 & 0.549 \\
\hline Annual Household Income & & & -0.086 & 0.063 \\
\hline Highest Degree & & & -0.064 & 0.081 \\
\hline $\begin{array}{l}\text { Race }(1=\text { white; } 0=\text { not } \\
\text { white) }\end{array}$ & & & $-1.019 * *$ & 0.373 \\
\hline $\mathrm{N}$ & 3749 & & 3663 & \\
\hline
\end{tabular}

Table 7 results suggest that other people's perception of the respondents' gender $(\mathrm{p}=0.016)$ is a significant predictor for being physically assaulted at mental health clinics. Persons who report that others are always able to tell they are transgender or gender nonconforming are 2.747 as likely $(\operatorname{Exp}(1.010)=2.747)$ as person where others are not always able to tell they are transgender or gender non-conforming to experience being physically assaulted at mental health clinics. Model 2 adds gross annual household income (in dollars), the respondent's highest education level completed, and whether or not they identify as white. Model 2 reveals that others' perception of their gender is no longer a significant predictor. Unlike previous regressions, race is a statistically significant indicator $(\mathrm{p}=0.006)$. Persons who identify as white are 0.361 as likely $(\operatorname{Exp}(-1.019)=.361)$ as persons who do not identify as white to be physically assaulted at mental health clinics. 
Previous literature has suggested that transmen (FTM) and transwomen (MTF) have different experiences (Connell 2010; Schilt 2010). Studies that have found differences between transmen and transwomen have looked at people who self identify as transman (FTM) or transwoman (MTF). Given this, I conducted a logistic regression models to analyze the likelihood of discrimination in mental health clinics for selfidentified FTM and MTF people. I recoded the variables FTM and MTF into dichotomous variables where 1 is where respondents strongly identify as MTF or FTM and 0 is where they do not identify or somewhat identify as MTF or FTM. I chose this due to previous literature, which looked at people who self-identify with these terms, implying that they "strongly" identify. I excluded all other identities from these multivariate analyses, given I am only interested in considering the differences between transmen (FTM) and transwomen (MTF).

Table 8: Logistic Regression Coefficients Predicting Being Denied Equal Treatment $(1=$ denied equal treatment; $0=$ not denied equal treatment)

\begin{tabular}{lcrrc}
\hline & \multicolumn{3}{c}{ Model 1 } & \\
\hline & B & S.E. & B & \multicolumn{1}{c}{ S.E. } \\
(Constant) & $-2.330^{* *}$ & 0.125 & $-1.683^{* *}$ & 0.239 \\
FTM (reference: MTF) & 0.088 & 0.067 & 0.040 & 0.069 \\
Annual Household Income & & & $-0.108^{* *}$ & 0.020 \\
Highest Degree & & & 0.008 & 0.029 \\
Race (1=white; 0=not & & & -0.145 & 0.154 \\
white) & \multirow{2}{*}{3206} & & 3139 & \\
N & & & & \\
\hline
\end{tabular}
$* \overline{p<0.05 * * p<0.01}$

Table 8 results suggest that identifying as FTM is not a significant predictor for being denied equal treatment at a mental health clinic. Model 2 considers gross annual household income (in dollars), highest level of education completed, and whether or not 
they identify as white. Model 2 is consistent with model 1 in that identifying as FTM is still not a significant predictor. However, annual household income is a significant predictor $(\mathrm{p}=0.00)$ for experiencing being denied services. Persons with a higher annual household income are $0.897(\operatorname{Exp}(-.108)=.897)$ as likely as persons with lower income to experience being denied services at mental health clinics.

Table 9: Logistic Regression Coefficients Predicting Being Verbally Harassed (1=verbally harassed; $0=$ verbally harassed)

\begin{tabular}{|c|c|c|c|c|}
\hline & Model 1 & & & \\
\hline & B & S.E. & B & S.E. \\
\hline (Constant) & $-2.427 * *$ & 0.123 & $-1.832 * *$ & 0.236 \\
\hline FTM (reference: MTF) & $0.182 * *$ & 0.064 & 0.125 & 0.066 \\
\hline Annual Household Income & & & $-0.110^{* *}$ & 0.020 \\
\hline Highest Degree & & & 0.017 & 0.028 \\
\hline $\begin{array}{l}\text { Race }(1=\text { white; } 0=\text { not } \\
\text { white) }\end{array}$ & & & -0.130 & 0.152 \\
\hline $\mathrm{N}$ & 3206 & & 3139 & \\
\hline
\end{tabular}

Table 9 suggests that identifying as FTM is a significant predictor $(\mathrm{p}=0.005)$ for being verbally harassed at mental health clinics. Persons who identify as FTM are 1.199 $(\operatorname{Exp}(.182)=1.199)$ as likely as persons who identify as MTF to experience being verbally harassed at mental health clinics. However, this is only a significant predictor when not considering any other factors. Model 2 reveals that when considering income, education, and race, identifying as FTM is no longer a significant predictor. Instead, annual household income $(\mathrm{p}=0.00)$ are significant predictors of being verbally harassed at mental health clinics. Persons with a higher annual household income are 0.896 (Exp($.110)=.896$ ) as likely as persons with lower income to experience being verbally harassed at mental health clinics. 


\begin{tabular}{|c|c|c|c|c|}
\hline & Model 1 & & el 2 & \\
\hline & $B$ & S.E. & $B$ & S.E. \\
\hline (Constant) & $-4.921 * *$ & 0.406 & $-2.660 * *$ & 0.652 \\
\hline FTM (reference: MTF) & 0.116 & 0.214 & -0.038 & 0.234 \\
\hline $\begin{array}{l}\text { Annual Household } \\
\text { Income }\end{array}$ & & & -0.132 & 0.077 \\
\hline Highest Degree & & & -0.151 & 0.092 \\
\hline $\begin{array}{l}\text { Race ( } 1=\text { white; } 0=\text { not } \\
\text { white) }\end{array}$ & & & -0.769 & 0.427 \\
\hline $\mathrm{N}$ & 3206 & & 3139 & \\
\hline
\end{tabular}

Table 10 suggests that identifying as FTM is a not significant predictor for being physically assaulted at mental health clinics. Model 2 reveals that identifying as FTM is still not a significant predictor when considering race, income, and education. Model 1 and 2 reveal that no variable ran in these analyses were significant predictors for being physically assaulted at mental health clinics. It is possible that there is another factor contributing to respondents' experiencing physical assault.

Logistic regressions suggest that other people's perception of the respondents' gender is a significant predictor for being physically assaulted at mental health clinics. When also controlling for race, education level, and income, other people's perception of the respondents' gender is no longer a significant predictor. Rather, income is a significant predictor for being denied services and being verbally harassed and whether or not someone identifies as white is a significant predictor for being physically assaulted at mental health clinics. Logistic regressions analyzing the experiences between people who identify as FTM and those who identify as MTF reveal that FTM identity is only significant for being verbally harassed at mental health clinics. FTM identity is no longer 
a significant predictor when controlling for race, education, and income. Rather, annual household income is a significant predictor for being denied services and being verbally harassed at mental health clinics. There were no significant predictors for being physically assaulted at mental health clinics, suggesting that there could be another factor influencing why this form of discrimination is occurring. 


\section{DISCUSSION}

Meyer (2003)'s theory of minority stress argues that stigma, prejudice, and discrimination cause mental health problems among LGB populations. This theory has since been expanded to include transgender and gender non-conforming people (Hendricks \& Testa 2012). This study specifically considered the associations between gender identity, stigma visibility (if others can tell they are transgender), and discrimination. This is important due to the established literature that demonstrates negative social environments (such as physical and sexual violence, discrimination, etc.) affect access to and engagement in mental health services and mental health outcomes (suicide, substance abuse, etc.) (Hendricks \& Testa 2012). However, the deviation from gender norms may be the root of why transpeople are experiencing discrimination.

\section{Gender Identity and Discrimination}

The first research question included: How do various gender identities, among gender non-conforming individuals, affect perceived discrimination at mental health clinics? Overall, the results of this study suggest that there is an association between gender identity and reports of discrimination at mental health clinics. The association varies depending on which form of discrimination (being denied services, verbally harassed, or physically assaulted), which gender term an individual identifies with, and the degree to which they identify with the term.

Identifying with the terms FTM (female-to-male) and gender non-conforming had statistically significant results for individuals reporting that they had been denied services or equal treatment at mental health clinics. However, those who somewhat identified as FTM reported experiencing being denied services more than those who do not identify or 
strongly identify as FTM. Respondents who strongly identify as gender non-conforming report being denied services more than those who do not or somewhat identify as gender non-conforming. This could suggest that either partially or sometimes identifying as FTM could be an indicator of the extent and individual's gender expression aligns with the gender binary. This parallels this study's findings of bivariate analyses that considered FTM identity and other people's perception of their transgender or gender nonconforming identity. The bivariate analysis revealed that respondents who reported that others are able to tell they are transgender or gender non-conforming most of the time or always reported that they sometimes identify with the term FTM. Individuals who somewhat identify as FTM or strongly identify as gender non-conforming may experience being denied services because they are challenging gender boundaries, as they do not fit under a stealth performance where they are held to the same gender expectations as cisgender people (Connell 2010; Schilt 2010). There is little research on those who somewhat or partially identify with non-binary gender identities. It is possible that those who somewhat identify as FTM are still in the process of developing their gender identity and discovering what these terms mean to them, or that they are attempting to create a hybrid of gender expression (Connell 2010).

In contrast, identifying with the terms MTF (male-to-female) or transgender had statistically significant results for being physically assaulted at mental health clinics. The degree to which an individual identifies with a term is important. Participants who somewhat identified as MTF reported more than those who do not or strongly identify as MTF that they experience being physically assaulted at mental health clinics. Participants who strongly identify as transgender report being physically assaulted at mental health 
clinics than those who do not or somewhat identify as transgender. Similar to those who somewhat identifying as FTM experiencing being denied services, those who somewhat identify as MTF may experience physical assault due to challenging gender boundaries. If an individual does not fully identify as MTF then it is unlikely that they fit under a stealth performance (Connell 2010; Schilt 2010). Bivariate analyses of MTF identity and others' perception of their transgender or gender non-conforming identity suggests that persons who somewhat identify as MTF report that others can tell they are transgender or gender non-conforming sometimes or occasionally. Individuals who somewhat identify as MTF may be more visibly gender non-conforming or attempting to create a hybrid of gender expression (Connell 2010). This finding is also in line with previous research that finds transwomen have different experiences from transmen, in that they are often subordinated in an overall attempt to maintain a gender status quo (Connell 2010; Schilt 2010).

Multiple identities were statistically significant for reporting that they had been verbally harassed at mental health clinics. These identities include: FTM, MTF, gender non-conforming, and genderqueer. The degree to which an individual identifies with each of these terms is important. For the identities gender non-conforming and genderqueer, respondents who strongly identified with each of these terms reported more often than those who did not or somewhat identified with these terms to experience being verbally harassed at mental health clinics. For the identities FTM and MTF, participants who somewhat identified as FTM or MTF reported more than those who did not or who strongly identify as FTM or MTF that they experienced being verbally harassed. The degree to which an individual identifies with each term may or may not be due to if 
others can tell they are transgender or gender non-conforming. While previous research has not always considered the degree to which an individual identified with a term, Sperber et al. (2005) also found that FTM youth experience verbal abuse frequently from receptionists who laugh or whisper about their gender presentation. Sperber et al.'s (2005) study was of transpeople's experiences with the health care system in general, but it appears that this is still applicable to the mental health system as well. It is unclear in this study who is verbally harassing FTM participants, and future research should include who is discriminating against transpeople.

Bivariate analyses of identity and others' perception revealed statistically significant results that others are able to tell they are transgender or gender nonconforming occasionally if they strongly identify as transsexual, most of the time or always if they somewhat identify as FTM, always or most of the time if they strongly identify as gender non-conforming, and most of the time or sometimes if they strongly identify as genderqueer. However, these results to not align with bivariate analyses of others' perception and being verbally harassed at mental health clinics, which was not statistically significant. Therefore, it is possible that Connell (2010) and Schilt's (2010) discussion of performing stealth compared to an attempt to create a hybrid gender expression could be applicable to these participants who had been verbally harassed at mental health clinics. The multiple identities experiencing being verbally harassed may also be due to transpeople reporting more verbal insults, such as in Fredrikson-Goldsen et al.'s (2013) study. More may be known about individuals being verbally harassed and being denied services because these could be more common forms of discrimination. 
This is parallel to Kosenko et al. (2013) study that found transpeople were often denied services, and when they were not denied services they were often verbally abused.

Multivariate analyses compared the experiences of participants who strongly identified as MTF or FTM. Results suggest that identifying as FTM was a significant predictor for being verbally harassed at mental health clinics. Both Fredrikson-Goldsen et al. (2013) and Kosenko et al.'s (2013) studies found that transpeople report more verbal insults or verbal abuse, suggesting this may be a more common form of discrimination. Identifying as FTM was not a significant predictor for any form of discrimination when controlling for income, race, and education. Income was a predictor for participants being denied services and verbally harassed. Identifying as FTM, income, race, and education were not significant predictors for being physically assaulted at mental health clinics.

\section{Others' Perception and Discrimination}

The second research question included: How does others' perception of gender non-conformity affect transgender and gender non-conforming individuals' reports of discrimination at mental health clinics? The results from this study varied on whether or not there was an association between discrimination at mental health clinics and the participants' reports of if others can tell they are transgender or gender non-conforming. Results differed between bivariate and multivariate analyses, type of discrimination, and when other variables were controlled for (such as education, income, and race).

Results for bivariate analyses revealed that there is an association between discrimination at mental health clinics and the participants' reports of if others can tell they are transgender or gender non-conforming. However, this depends on the type of discrimination. Other people's perception of their gender identity was statistically 
significant for being physically assaulted. Others' perception was not statistically significant for being denied services or verbally harassed at mental health clinics. These results are in line with Miller and Grollman's (2015) study on the connection between gender non-conformity, discrimination, and health-harming behaviors. They found that gender non-conforming trans adults reported more transphobic discrimination than transpeople who are gender conforming, which reveals that stigma visibility (such as visibly outside of the gender binary) plays a role in transpeople's outcomes (Miller \& Grollman 2015). However, Miller and Grollman (2015) defined discrimination different from this study; they looked at discrimination across multiple institutions and considered major discrimination (fired, denied health care, etc.) and everyday discrimination (harassed, treated unfairly, etc.). Therefore, the findings parallel their study, but are specific to mental health clinics.

Multivariate analyses suggested similar results as bivariate analyses, such that other people's perception of the respondents' gender is a significant predictor for being physically assaulted at mental health clinics. However, when controlling for race, education level, and income, other people's perception of the respondents' gender is no longer a significant predictor. Rather, income is a significant predictor for being denied services and being verbally harassed and whether or not someone identifies as white is a significant predictor for being physically assaulted at mental health clinics. This suggests that the multiple identities that an individual has, such as their income level or race, are sometimes more salient than their gender identity or expression. This can be because if an individual has more than one minority status (gender identity and racial minority), their experiences of discrimination can be exacerbated. Schilt (2010) found that being 
transgender and a racial minority results in being held to not only gender stereotypes, but also racial stereotypes. Lombardi et al. (2002) argue that there is a connection between economic discrimination and gender violence, which explains why income is a significant predictor for discrimination at mental health clinics. Multivariate analyses depart from Miller and Grollman's (2015) findings that suggested stigma visibility (gender nonconformity) affects who is at risk for experiencing discrimination. The findings of this study suggest that stigma visibility plays a role, but income and race are significant predictors for transpeople experiencing discrimination.

The degree to which a person identifies with a gender identity and if they are visibly transgender can help to confuse the use of gender as a primary frame for interactions (Ridgeway 2011). If gender is used as one of the primary frames for an interaction, then an individual will categorize the transgender or gender non-conforming individual into a specific gender and use that as a frame for how they should interact with one another. But if the transgender person somewhat identifies with a gender identity, is still exploring gender identities and expressions, or does not fit clearly within the binary, then another person may have difficulty placing them into a category to help frame their interaction. Any expectation for how the transgender person will behave will no longer have a specific gender associated with the behaviors. The inability to categorize a person into a specific gender is problematic because gender is a primary frame for interactions and individuals evaluate their social interactions with one another based on categorizations for gender. The behaviors we associate with gender are considered a performance, were we "do" gender in order to legitimize and reproduce the initial division of one's sex (West \& Zimmerman 1987). When the performance and 
categorization of another person's gender do not align, this denies an individual's ability to pass as their sex assigned at birth (West \& Zimmerman 1987). Every person, including transpeople, are under constant scrutiny and evaluation of their gender performance (West \& Zimmerman 1987). This is further exacerbated by gender expression, which can be a visible marker of one's gender non-conformity, and allows for others to be able to tell if someone is transgender or gender non-conforming (Miller \& Grollman 2015). This helps to explain why respondents primarily reported being denied equal treatment or services and being verbally harassed at mental health clinics. For transpeople, particularly those who somewhat identify with an identity and are visibly trans, they may challenge the gender binary. Their gender performance does not help to support and reproduce the initial division of one's sex. This poses problems in interactions with others who are likely less aware of the variation of gender identities and expressions that exist. Since many mental health providers are not taught about transgender identity, the changes to the DSM-V, without adequate training and education on the nuances of transgender identity, do little to combat the idea of transgender identity as being a medical condition, and does not educate health care providers about gender variance (Johnson 2015). Therefore, some mental health providers may still hold transgender people accountable to the diagnostic criteria and deny them gender-affirming medical care (Johnson 2015). Mental health providers may also hold transpeople to the idea that transpeople are "born in the wrong body" and fail to recognize the variation of gender identities and expressions among transpeople (Johnson 2015).

The results of the current study provide support for that Meyer's (2003) theory of minority stress. Minority stress suggests that there is a connection between an 
individual's minority identity (such as transgender or gender non-conforming), discrimination, and negative health outcomes. In addition to conforming Meyer's (2003) theory, the current study also illustrates that the association between minority identity and discrimination is complex. An individual's (minority) gender identity is influenced by which gender identity term they identify with, the degree to which they identify with the term, and how others' perceive their gender identity. This indicates that transgender and gender-nonconforming identity are complex and influence various outcomes, such as verbal harassment, physical assault, and denial of services at mental health clinics.

\section{Limitations}

Using the 2008 National Transgender Discrimination survey in order to conduct my analyses has its strengths and weaknesses. This dataset is the "most extensive survey of transgender discrimination ever undertaken" (National Center for Transgender Equality 2014). The strength of this is that this dataset provides a breadth of information on a population that is often under-researched, however it is not generalizable to the entire transgender population. The weakness of this survey is that it was conducted before the changes of pathology in the DSM-V. Therefore, during 2008 being transgender or gender non-conforming was pathologized within the mental health field. The changes to the DSM-V still allow for diagnosis, but the terminology and criteria have changed in an attempt to decrease the stigma on gender variance while still allowing for the ability to report diagnoses for insurance purposes. Therefore, it is unknown if the changes to the DSM in 2013 have made any substantial changes on treatment of transpeople or utilization of services at mental health clinics. It is possible that many transpeople avoid seeking services in fear of being diagnosed, misunderstood, or discriminated against. It is 
possible that this may have influenced the results of the present study and that this may be different for transpeople after the changes in the DSM in 2013. However, the National Center for Transgender Equality and the National LGBTQ Task Force, who created the first NTDS, are currently working on the second iteration of the survey which will be released later in 2016.

The operationalization of discrimination was determined by the original survey as including: denied equal treatment or service, verbally harassed or disrespected, and being physically attacked or assaulted. This may not be a fully comprehensive way to define discrimination. Discrimination could also include situations where individual's felt they were treated differently. For example, they could have felt a counselor or therapist treated them differently due to being transgender, but they still received services and were not physically or verbally attacked. Respondents were also only asked if they experienced these forms of discrimination at a mental health clinic. However, this does not reveal how they knew the discrimination was due to their transgender identity, who was discriminating against them (receptionist, another patient, etc.), or even the location within the mental health clinic that it occurred (in the parking lot, waiting room, etc.). In order to understand participant's gender identity, the original survey asked them to check the degree to which they identified with each term (transgender, transsexual, etc.). Each identity was not mutually exclusive. For example, a participant could identify strongly as transgender, somewhat as genderqueer, and not at all as transsexual. While this provides a larger understanding of the multiplicity of identities each person identifies with, it poses limitations in understanding the main identity an 
individual felt is most salient for them. For example, the question participants were asked allows for them to possibly strongly identify with multiple and possibly all identities.

\section{Future Research}

The results of the current study demonstrate that the relationship between transgender identity and discrimination at mental health clinics is multifaceted. Nonprobability samples help to provide useful information that expands research, such as knowledge on the transgender population, and can provide suggestions or relationships among variables and generate hypotheses for future research (Institute of Medicine 2011). This study contributes to current research by confirming that there is a relationship between a person's gender identity and others' perception of their gender identity. Future research should continue to look at the role others' perception of an individual's gender identity plays in discrimination. In addition, the degree to which an individual identifies with a gender identity term is important. Research utilizing Meyer's (2003) minority stress theory should include a more in-depth consideration for the complexities of having a minority identity and how this could be influenced by self-identification, the degree they identify with a term, and how other's perceive their identity.

Additionally, there is little previous research on gender non-conformity, specifically identities such as genderqueer. Future research should include these populations in order to better understand how their experiences are similar or different from other identities within the transgender community. Future research should utilize qualitative methods in order to better understand how discrimination is taking place at mental health clinics for transgender people. Conducting in-depth qualitative studies of the experiences of transpeople in mental health clinics may reveal more information on how the type (i.e., 
private practice vs. free clinic), and location (i.e., rural, urban, suburban region) of the mental health clinic may influence the experiences of transpeople using those services. Additional studies should aim to assess the factors that cause transgender and gender non-conforming people to stop using mental health services, in hopes of continuing to strengthen our understanding of the gaps in services for transgender and gender nonconforming people. Qualitative methods can also be used to understand how income and race intersect with an individual's gender identity and expression and how this affects their experiences and outcomes with mental health services.

\section{Conclusion}

There is an association between gender non-conforming identities, other people's perception of one's gender identity, and discrimination at mental health clinics. These associations differ depending on an individual's gender identity and the strength of that identity, such as if they somewhat or strongly identify with a term. These associations also depend on the form of discrimination, such as being denied services or verbally harassed. For someone who is in the transgender population, understanding which terms and the degree to which they identify with the terms is important. Other people's perception of their gender identity is important, as stigma visibility can affect if someone experiences discrimination. Future research should include others' perception of an individual's gender identity and be inclusive of more gender non-conforming identities, such as genderqueer. It is important for future research to look at differences within the transgender community, beyond just differences between transmen and transwomen. The present study illuminates the importance of the role of training for mental health providers. All mental health providers should be knowledgeable of the variation in 
transgender and gender non-conforming identities, and trained on the mental health needs of these communities in order to ensure that transgender and gender non-conforming people are not mistreated and receive proper services when visiting a mental health clinic. Trainings can also provide therapists and staff with information on how the variation in gender identities affect people's experiences with mental health clinics. All in-take forms should include options for transgender and gender non-conforming individuals to make sure that mental health providers are aware of how an individual identifies and their preferred gender pronouns prior to their initial interaction. Each of these recommendations are a step in the right direction towards ensuring that transgender and gender non-conforming people receive equitable and comprehensive mental health services. 


\section{REFERENCES}

American Psychiatric Association. 2013. Diagnostic and Statistical Manual Of Mental Disorders. Washington, D.C.: American Psychiatric Publishing.

American Psychiatric Association. 2013. "Gender Dysphoria." Retrieved Feb. 18, 2015 (http://www.dsm5.org/Documents/Gender\%20Dysphoria\%20Fact\%20Sheet.pdf).

American Psychiatric Association. 2013. "Highlights of Changes from DSM-IV-TR to DSM-5.” Retrieved Feb. 18, 2015

(http://www.dsm5.org/Documents/changes $\% 20$ from $\% 20 \mathrm{dsm}$-iv-tr $\% 20$ to $\% 20 \mathrm{dsm}$ 5.pdf).

Balsam, Kimberly, Yamile Molina, Blair Beadnell, Jane Simoni, and Karina Walters. 2011. "Measuring Multiple Minority Stress: The LGBT People of Color Microaggressions Scale." Cultural Diversity and Ethnic Minority Psychology 17 (2): 163-174.

Brickell, Chris. 2006. "The Sociological Construction of Gender and Sexuality." The Sociological Review.

Bryant, Karl. 2005. "Review: Shifting Paradigms? Making the Move to Transgender Clinical Practices." The Journal of Sex Research 42 (4): 367-369).

Centers for Disease Control and Prevention. 2015. "Youth Suicide." http://www.cdc.gov/violenceprevention/pub/youth suicide.html

Clements-Nolle, Kristen, Rani Marx, and Mitchell Katz. 2006. "Attempted Suicide Among Transgender Persons." Journal of Homosexuality 51: 3, 53-69.

Connell, Catherine. 2010. "Doing, Undoing, or Redoing Gender? Learning from the Workplace Experiences of Transpeople." Gender and Society 24 (1): 31-55.

Cook-Daniels, Loree. 1998. "Lesbian, Gay Male, Bisexual, and Transgendered Elders: Elder Abuse and Neglect Issues." Journal of Elder Abuse \& Neglect 9: 2, 35-49.

Eliason, Michele, Suzanne Dibble, Jeanne DeJoseph, Peggy Chinn. LGBTQ Cultures: What Health Care Professionals Need to Know about Sexual and Gender Diversity.

Epstein, Cynthia. 2007. "Great Divides: The Cultural, Cognitive, and Social Bases of the Global Subordination of Women." American Sociological Review 72 (1): 1-22.

Equal Employment Opportunity Commission. "Facts about Discrimination in Federal Government Employment Based on Marital Status, Political Affiliation, Status as a Parent, Sexual Orientation, or Transgender (Gender Identity) Status." http://www.eeoc.gov/federal/otherprotections.cfm

Equal Employment Opportunity Commission. "Sex-Based Discrimination." http://www.eeoc.gov/laws/types/sex.cfm

Fredriksen-Goldsen, Karen, Loree Cook-Daniels, Hyun-Jun Kim, Elana Erosheva, Charles Emlet, Charles Hoy-Ellis, Jayn Goldsen, and Anna Muraco. 2013. "Physical and Mental Health of Transgender Older Adults: An At-Risk and Underserved Population." The Gerontologist 54 (3): 488-500.

Gamarel, Kristi, Sari Resiner, Jean-Philippe Laurenceau, and Tooru Nemoto. 2014. "Gender Minority Stress, Mental Health, and Relationship Quality: A Dyadic Investigation of Transgender Women and Their Cisgender Male Partners." Journal of Family Psychology 28 (4): 437-447. 
Gates, Gary. 2011. "How Many People are Lesbian, Gay, Bisexual, and Transgender?" The Williams Institute.

Grant, Jaime, Lisa Mottet, Justin Tanis, Jack Harrison, Jody Herman, and Mara Keisling. 2011. "Injustice at Every Turn: A Report of the National Transgender Discrimination Survey." Washington: National Center for Transgender Equality and National Gay and Lesbian Task Force.

Grossman, Arnold, and Anthony D’augelli. 2006. “Transgender Youth.” Journal of Homosexuality 51 (1):111-128.

Grossman, Arnold, and Anthony D'augelli. 2007. "Transgender Youth and LifeThreatening Behaviors.” The American Association of Suicidology 37(5): 527537.

Henricks, Michael, and Rylan Testa. 2012. "A Conceptual Framework for Clinical Work with Transgender and Gender Nonconforming Clients: An Adaptation of the Minority Stress Model." Professional Psychology: Research and Practice 43 (5): 460-467.

Human Rights Campaign. 2013. "Transgender Workers at Greater Risk of Unemployment and Poverty." http://www.hrc.org/blog/transgender-workers-atgreater-risk-for-unemployment-and-poverty

Institute of Medicine of the National Academies. 2011. The Health of Lesbian, Gay, Bisexual, and Transgender People. Washington, DC: The National Academies Press.

Johnson, Austin. 2015. "Normative Accountability: How the Medical Model Influences Transgender Identities and Experiences." Sociology Compass 9: 803-813.

Johnson, Carey, Matthew Mimiaga, and Judith Bradford. 2008. "Health Care Issues Among Lesbian, Gay, Bisexual, Transgender and Intersex (LGBTI) Populations in the United States: Introduction." Journal of Homosexuality 54 (3): 213-224.

Kosenko, Kami, Lance Rintamaki, Stephanie Raney, and Kathleen Maness. 2013. "Transgender Patient Perceptions of Stigma in Health Care Contexts." Medical Care 51 (9): 819-822.

Lombardi, Emilia, Riki Anne Wilchins, Dana Prising, and Diana Malouf. 2002. "Gender Violence." Journal of Homosexuality 42 (1): 89-101.

Meyer, Ilan. 2003. "Prejudice, Social Stress, and Mental Health in Lesbian, Gay and Bisexual Populations: Conceptual Issues and Research Evidence." Psychol Bull 125 (5): 674-697.

Miller, Lisa, and Eric Anthony Grollman. 2015. "The Social Costs of Gender Nonconformity for Transgender Adults: Implications for Discrimination and Health." Sociological Forum 30 (3): 809-831.

Nadal, Kevin. 2013. That's So Gay! Microaggressions and the Lesbian, Gay, Bisexual, and Transgender Community. Washington, DC: American Sociological Association.

National Center for Transgender Equality. 2014. "Injustice at Every Turn: Report of the National Transgender Discrimination Survey." Retrived Feb. 26, 2015 (http://endtransdiscrimination.org/report.html).

National Center for Transgender Equality. 2014. "Transgender Terminology." Retrieved Feb. 18, 2015 (http://transequality.org/Resources/TransTerminology 2014.pdf). 
Ridgeway, Cecilia. 2011. Framed by Gender: How Gender Inequality Persists in the Modern World. New York, New York: Oxford University Press, Inc.

Schilt, Kristen. 2010. Just One of the Guys: Transgender Men and the Persistence of Gender Inequality. Chicago: University of Chicago Press.

Sperber, Jodi, Stewert Landers, and Susan Lawrence. 2005. "Access to Health Care for Transgendered Persons: Results of a Needs Assessment in Boston." International Journal of Transgenderism 8: 2-3, 75-91.

West, Candace, and Don Zimmerman. 1987. "Doing Gender." Gender and Society 1 (2): 125-151.

Youth Suicide Prevention Program. 2011. "Statistics about Youth Suicide." Retrieved Feb. 18, 2015 (http://www.yspp.org/about suicide/statistics.htm). 